\title{
Spatial Distribution and Modeling of Soil Transmitted Helminthes Infection in Nigeria
}

\author{
Clement Ameh Yaro ${ }^{1,2^{*}}$, Ezekiel Kogi², Sodangi Abdulkarim Luka² \\ ${ }^{1}$ Department of Animal Science and Environmental Biology, Kogi State University, Anyigba, Kogi State, Nigeria \\ ${ }^{2}$ Department of Zoology, Ahmadu Bello University, Zaria, Nigeria \\ Email: *acyarocity@yahoo.com
}

How to cite this paper: Yaro, C.A., Kogi, E. and Luka, S.A. (2018) Spatial Distribution and Modeling of Soil Transmitted Helminthes Infection in Nigeria. Advances in Infectious Diseases, 8, 82-107. https://doi.org/10.4236/aid.2018.82010

Received: July 24, 2017

Accepted: June 22, 2018

Published: June 25, 2018

Copyright ( 92018 by authors and Scientific Research Publishing Inc. This work is licensed under the Creative Commons Attribution International License (CC BY 4.0).

http://creativecommons.org/licenses/by/4.0/

(c) (i) Open Access

\begin{abstract}
Background and Objective: Soil transmitted helminthes (STH) infection affects more than two billion people worldwide with Nigeria having the highest burden in Sub-Saharan Africa. This study examined the spatial and potential distribution of STHs in Nigeria. Materials and Methods: Secondary data were assessed from 98 journals and the prevalence of Ascaris lumbricoides, Trichuris trichiura and hookworms were extracted from them. The spatial distribution of the parasites was performed using DIVA-GIS software. The climatic variables (temperature and precipitation) and elevation variable (altitude) were used in the modeling of the parasites using Maximum Entropy (MaxEnt) modeling tool. Results: The average prevalence of $A$. lumbricoides, Hookworms and T. trichiura in Nigeria is $25.17 \%, 16.86 \%$ and $9.74 \%$ respectively. Delta State $(62.08 \%)$ had the highest infection of $A$. lumbricoides followed by Oyo (55.50\%) and Kano (44.40\%) while 14 states had prevalence of below 20.0\%. Akwa Ibom and Kano States had the highest average prevalence of $55.80 \%$ for hookworm infections. Delta, Oyo and Benue States had prevalence of $38.08 \%, 35.80 \%$, and $35.40 \%$ respectively while 22 states had prevalence of hookworm below $20.0 \%$. T. trichiura had the least average prevalence among the three STHs. Akwa Ibom State had the highest prevalence for this parasite with $40.40 \%$ followed by Lagos, Delta and Kwara States with prevalence values of $24.85 \%, 24.05 \%$ and $23.37 \%$ respectively. Other states in the Federation had prevalence values of less than $12 \%$ with Federal Capital Territory (FCT), Abuja and Borno States having the least prevalence of 0.80 and $0.90 \%$ respectively. The potential distribution that reveals than southern Nigeria has been at high risk of infections. Precipitations of the wettest month, altitude, precipitation of the warmest quarter are the major environmental variables that affect the distribution of STH. Conclusion: Nigeria is characterized by varying prevalence of STHs. All states in Nigeria are endemic for STHs. Southern Nigeria was observed to have higher prevalence of STHs due
\end{abstract}


to the high level of precipitation and low altitude of these regions. "The higher the altitude, the lower the prevalence of STH infections. The higher the temperature and precipitation, the higher the prevalence of STH infections.

\section{Keywords}

MaxEnt, Altitude, Temperature, Precipitation, Soil Transmitted Helminths

\section{Introduction}

Soil-transmitted helminths (STHs) (Ascaris lumbricoides, hookworm and Trichuris trichiura) are responsible for more than $40 \%$ of the worldwide morbidity from all tropical infections [1]. STH is ranked first among the seven neglected tropical diseases (NTDs) most prevalent in Nigeria as having the highest burden on the population [2]. Social-ecological systems govern the transmission of STH and thriving in areas with poor sanitation and hygiene [3]. Hotez et al. [4] and Oluwole et al. [5] reported that Nigeria has the highest infected people with STH in sub-Saharan Africa with children of age 5 - 14 years at high risk of infection and morbidity. Despite the recognition of the importance of STH infections coupled with the control strategies, the infections from these parasites still remain the major cause of malnutrition, iron-deficiency and anaemia in Nigeria [2] and children co-infected with these parasites have been shown to have hampered cognitive and physical development that leads to inefficiency in learning and school achievements [6] [7]. The Federal Ministry of Health, Nigeria in 2012 highlighted the need to scale-up interventions across NTDs programmes in their five-year master plan due to the impact of these parasites.

The use of geospatial health resource data and improved software analysis to produce low-cost digital health maps and transmission models for tropical diseases was encouraged by Malone [8] as these models helped policy makers and researchers in the health sector to concentrate in areas of high risks thereby helping to reduce operational cost.

Predictive modelling of infection geographic distributions by using environmental conditions of sites of known occurrence constitutes an important technique in analytical biology and its applications in epidemiology are enormous [9]. Predictions of infection risk areas where prevalence data are lacking can also be supplied by spatial statistical models [10].

Maximum entropy (MaxEnt) modeling is a general-purpose method for making predictions of inferences from incomplete information [11]. Maximum entropy modeling is useful in epidemiology as it allows the use of presence-only datasets [11] making it of merit for research and development in parasitology which usually has presence-only datasets [12]. The uses of modeling techniques such as MaxEnt that require only presence data are therefore extremely valuable [13]. MaxEnt modeling technique also allows the use of both continuous and categorical data that enables interaction between variables [14] producing a bet- 
ter visualization of results on maps.

Although, spatial and potential distribution of STHs was carried out by Oluwole et al. [5] using survey data obtained by the Federal Ministry of Health, Nigeria in the year 2011, the need to updated and use other data obtained from different parts of the country to assess the distribution of these parasites would help to improve existing distribution maps. This study will help to identify areas of high suitability for soil transmitted helminth infections as well as rank environmental variables according to their relative importance in the determination of infections.

The purpose of study was to assess the spatial and potential distribution of Ascaris lumbricoides, Trichuris trichiura and hookworms under present climate change by using DIVA-GIS (an open access Geographic Information System for mapping and visualization) and MaxEnt ecological niche modeling tools.

\section{Materials and Methods}

\subsection{Ethics Statement}

Data used for this study are secondary data. Therefore, no specific ethical approval was required.

\subsection{STH Infection Data}

Literature searches were performed on http://www.google.com.ng to assess the prevalence of soil transmitted helminthes in Nigeria. A total of 98 journal articles published from year 2005 to 2017 were downloaded from the internet and the prevalence of Ascaris lumbricoides, Trichuris trichiura and Hookworms were extracted from them.

\subsection{Environmental Data}

The climatic variables such as temperature and precipitation influenced global and meso scales and topographic variables such as altitude and aspect that likely affects species distributions at meso and topo-scales while land-cover variables like percent canopy cover influence distributions at the micro-scale [11]. Hence, the use of the climatic and topographic variables in the prediction of distributions of soil transmitted parasites was used in Nigeria.

In this study, a total of 19 bioclimatic variables of present climate (1950-2000) for Nigeria were downloaded from http://www.worldclim.org/ at $1 \mathrm{~km}$ spatial resolution i.e. Worldclim database version 1.4 and were used in the prediction of soil transmitted helminthes distribution; BIO1-Annual Mean Temperature, BIO2-Mean Diurnal Range, BIO3-Isothermality, BIO4-Temperature Seasonality, BIO5-Maximum Temperature of Warmest Month, BIO6-Minimum Temperature of the Coldest Month, BIO7-Temperature Annual Range, BIO8-Mean Temperature of Wettest Quarter, BIO9-Mean Temperature of Driest Quarter, BIO10-Mean Temperature of Warmest Quarter, BIO11-Mean Temperature of Coldest Quarter, BIO12-Annual Precipitation, BIO13-Precipitation of Wettest 
Month, BIO14-Precipitation of Driest Month, BIO15-Precipitation Seasonality, BIO16-Precipitation of Wettest Quarter, BIO17-Precipitation of Driest Quarter, BIO18-Precipitation of Warmest Quarter and BIO19-Precipitation of Coldest Quarter. Elevation data derived from the Shuttle Radar Topography

Mission were also downloaded from

http://www.worldclim.org/. These bioclimatic variables can be summarized into 3 main variables: altitude, temperature and precipitation. Temperature and precipitation affect the rate of embryonation of STH parasites. As altitude increases, temperature also decreases, so highlands were colder and lowlands were warmer, which in turn affects the development rate of these parasites.

\subsection{Spatial Analysis of Soil Transmitted Helminthes}

Spatial distribution of STH in Nigeria was performed using Data-Interpolating Variational Analysis Geographic Information System (DIVA-GIS) software for Windows (version 7.5.0) downloaded from http://www.diva-gis.org/. The mean prevalence of each parasite; A. Iumbricoides, T. Trichiura and Hookworms were computed in Microsoft Excel version 2013 and converted to comma delimited files. These files were converted from text files to shape file files using DIVA-GIS and were geo-referenced on the map of Nigeria. The prevalence of these parasites were categorized $<5, \geq 5$ to $<10, \geq 10$ to $<20, \geq 20$ to $<40$ and $\geq 40$.

\subsection{Ecological Niche Modeling}

The potential distribution of soil transmitted helminthes parasites were modelled using MaxEnt software version 3.3.3k download from

http://www.cs.princeton.edu/ schapire/maxent/. MaxEnt uses environmental data at occurrence and background locations to predict the distribution of a species across a landscape [11] [15]. In this study, MaxEnt was used for mapping potential geographic distribution of soil transmitted helminthes in Nigeria. This modeling tool was selected based on the reasons of Sarma et al. [16]: it is present only modeling algorithm (i.e. absence data are not required), the performance has been relatively better than other modeling methods and the model has been hardly influenced by small sample sizes and hence prediction will be relatively robust. It has been shown to be among the top performing modeling tools by Elith et al. [17].

Probability of presence of each of the STH was estimated by MaxEnt using the mean prevalence of each of the STH obtained for all the states in Nigeria which serve as the presence records to generate background points that was used in finding the maximum entropy distribution [16]. Regularization of the prevalence was performed to control over-fitting. This modeling tool uses five different features to perform its statistics; linear, quadratic, product, threshold and hinge features to produce a geographical distribution of species within a define area. MaxEnt produces a logistic output format used in the production of a continuous map that provides visualization of graded prevalence with an estimated 
probability of acquiring infection with STH species between 0 and 1. This map distinguishes areas of high and low risk for STH infections [16].

The 19 environmental variables and the elevation data obtained were used for the ecological niche modeling. The level of significance of contribution of the altitude and 19 bioclimatic variables was used to calculate jackknife (a method of assessing the variability of data by repeating calculation on the sets of data obtained by removing one value from the complete set) and area under the receiver operating characteristics curve (AUC) was used to evaluate the model performance. The AUC values vary from 0.5 to 1.0 ; an AUC value of 0.5 showed that model predictions were not better than random, values $<0.5$ were worse than random, $0.5-0.7$ signifies poor performance, $0.7-0.9$ signifies reasonable/moderate performance and $>0.9$ indicates high model performance [18].

Model validation was performed according to Sarma et al. [16] as follows; using the "sub-sampling" procedure in MaxEnt. About 75\% of the parasites prevalence data were used for model calibration and the remaining $25 \%$ for model validation. Ten replicates were run and average AUC values for training and test datasets were calculated. Maximum iterations were set at 5000. Percent contribution (PC), permutation importance (PI) and jackknife procedures in MaxEnt were used to investigate the relative importance of different bioclimatic predictors. Sensitivity and specificity of infections were also measured. Sensitivity, which was also named the true positive rate, can measure the ability to correctly identify areas infected. Its value equals the rate of true positives and the sum value of true positives and false negatives. Specificity, which is also named the true negative rate, can measure the ability to correctly identify areas uninfected. Its value equals the rate of true negatives and the sum value of false positives and true negatives.

Data were analyzed using one-way analysis of variance (ANOVA), followed by Turkey's test. All statistical analyses were performed using the Statistical Package for Social Sciences (SPSS) software (version 21.0 for Windows; SPSS Inc., Chicago, IL). Statistical significance was set at $\mathrm{p}<0.05$. Map visualization were performed on DIVA-GIS 7.5.0 using grid file output of MaxEnt with the geographic area restricted Nigeria. Five classes of probabilities were given a specific color for visual representation of model results ranging from low risk to high risk: 0 - 0.10 (dark green), 0.10 - 0.20 (light green), 0.20 - 0.50 (yellow), 0.50 - 0.70 (orange) and $0.75-1$ (red).

\section{Results}

\subsection{Spatial Distribution of STH Infections in Nigeria}

The average prevalence of A. lumbricoides, Hookworms and T. trichiura in Nigeria were $25.17 \%, 16.86 \%$ and $9.74 \%$ respectively. While $A$. lumbricoides has the highest average prevalence (Table 1), these recorded occurrences of STH infections according to the states in Nigeria showed that for A. lumbricoides, Delta State $(62.08 \%)$ had the highest infection followed by Oyo $(55.50 \%)$ and 
Table 1. Mean Prevalence of $A$. Iumbricoides, T. trichiura and Hookworms in Nigeria.

\begin{tabular}{|c|c|c|c|c|c|}
\hline \multirow[b]{2}{*}{ S/No } & \multirow[b]{2}{*}{ State } & \multicolumn{3}{|c|}{ Mean $\% \pm$ S.E. } & \multirow[b]{2}{*}{ Authors } \\
\hline & & $\begin{array}{c}\text { Ascaris } \\
\text { lumbricoides }\end{array}$ & Hookworms & $\begin{array}{l}\text { Trichuris } \\
\text { trichiura }\end{array}$ & \\
\hline 1 & Abia & $18.50 \pm 9.19$ & $14.64 \pm 3.60$ & $10.39 \pm 5.69$ & $\begin{array}{l}\text { Nduka et al. [19], Wosu and Onyeabor [20], Kalu and Ihemanma [21], Ihemanma } \\
\text { and Oladele [22], Ezeigbo and Ezeigbo [23] }\end{array}$ \\
\hline 2 & Adamawa & $9.32 \pm 6.60$ & $8.95 \pm 4.76$ & $3.70 \pm 1.05$ & $\begin{array}{l}\text { Naphtali et al. [24] and Enimien et al. [25], Houmsou et al. [26], Oriakpono et al. } \\
\text { [27] and Naphtali et al. [28] }\end{array}$ \\
\hline 3 & $\begin{array}{l}\text { Akwa } \\
\text { Ibom }\end{array}$ & $36.07 \pm 18.14$ & $55.80 \pm 13.44$ & $40.40 \pm 29.99$ & Opara et al. [29], Usip and David [30], Usip and Matthew [31] \\
\hline 4 & Anambra & $19.23 \pm 7.68$ & $18.43 \pm 6.07$ & $4.73 \pm 1.07$ & $\begin{array}{l}\text { Chukwuma et al. [32], Ogbuagu et al. [33], Ezeagwuna et al. [34], Emmy-Egbe [35] } \\
\text { and Chioma et al. [36] }\end{array}$ \\
\hline 5 & Bauchi & NAD & NAD & NAD & \\
\hline 6 & Bayelsa & $35.15 \pm 0.15$ & $24.53 \pm 7.10$ & $7.80 \pm 6.10$ & Agi and Awi-Waadu [37], Bariweni et al. [38] and Bariweni et al. [39] \\
\hline 7 & Benue & NAD & $35.40 \pm 0.00$ & $3.80 \pm 0.00$ & Tyoalumun et al. [40] \\
\hline 8 & Borno & $2.30 \pm 1.30$ & $14.10 \pm 4.10$ & $0.90 \pm 0.00$ & Biu et al. [41] and Biu et al. [42] \\
\hline 9 & $\begin{array}{l}\text { Cross } \\
\text { River }\end{array}$ & $3.00 \pm 0.00$ & $5.60 \pm 0.00$ & $1.40 \pm 0.00$ & Usip and Ita [43] \\
\hline 10 & Delta & $62.08 \pm 8.60$ & $38.08 \pm 10.12$ & $24.05 \pm 3.04$ & $\begin{array}{l}\text { Egwunyenga and Ataikiru [44], Nmorsi et al. [45], Prosper et al. [46] and Ito and } \\
\text { Egwunyenga [47] }\end{array}$ \\
\hline 11 & Ebonyi & $38.19 \pm 6.78$ & $15.96 \pm 4.08$ & $9.52 \pm 2.54$ & $\begin{array}{l}\text { Uneke et al. [48], Ivoke et al. [49], Alo et al. [50], Dimejesi et al. [51], Ivoke et al. } \\
\text { [52], Okeke and Ubachukwu [53], Nnachi et al. [54] and Owaka and Njoku [55] }\end{array}$ \\
\hline 12 & Edo & $15.05 \pm 4.96$ & $6.47 \pm 1.34$ & $2.68 \pm 1.26$ & $\begin{array}{l}\text { Wagbatsoma and Aisien [56], Mordi and Paul [57], Oguanya et al. [58], Omorodion } \\
\text { et al. [59], Akinbo et al. [60], Nwaneri and Omuemu [61] and Ogbain-Emovon et al. } \\
\text { [62] }\end{array}$ \\
\hline 13 & Ekiti & NAD & NAD & NAD & \\
\hline 14 & Enugu & $22.84 \pm 12.54$ & $19.54 \pm 9.84$ & $11.53 \pm 10.73$ & Emeka [63], Ukwubile et al. [64], Aniwada et al. [65] and Uzodimma et al. [66] \\
\hline 15 & FCT & $2.50 \pm 0.00$ & $4.20 \pm 0.00$ & $0.80 \pm 0.00$ & Abayer et al. [67] \\
\hline 16 & Gombe & NAD & NAD & NAD & \\
\hline 17 & Imo & $22.76 \pm 5.94$ & $11.16 \pm 2.29$ & $5.83 \pm 1.62$ & $\begin{array}{l}\text { Kamalu et al. [68], Kalu et al. [69], Ezeigbo et al. [70], Udensi et al. [71], Kalu et al. } \\
\text { [72] and Iwunze et al. [73] }\end{array}$ \\
\hline 18 & Jigawa & $29.50 \pm 0.00$ & $24.30 \pm 0.00$ & $8.10 \pm 0.00$ & Yahaya et al. [74] \\
\hline 19 & Kaduna & $38.48 \pm 7.78$ & $10.38 \pm 3.98$ & $4.70 \pm 0.20$ & Auta et al. [75], Thomas et al. [76] and Auta et al. [77] \\
\hline 20 & Kano & $44.40 \pm 0.00$ & $55.80 \pm 0.00$ & NAD & Ahmad et al. [78] \\
\hline 21 & Katsina & NAD & NAD & NAD & \\
\hline 22 & Kebbi & $22.00 \pm 0.00$ & $10.00 \pm 0.00$ & $13.60 \pm 0.00$ & Oluwole et al. [79] \\
\hline 23 & Kogi & $22.00 \pm 0.00$ & $17.00 \pm 0.00$ & NAD & Ejima and Ajogun [80] \\
\hline 24 & Kwara & $19.11 \pm 5.57$ & $10.72 \pm 4.54$ & $23.37 \pm 17.36$ & $\begin{array}{l}\text { Babatunde et al. [81], Saka et al. [82], Babamale et al. [83], Amaechi et al. [84] and } \\
\text { Bolaji et al. [85] }\end{array}$ \\
\hline 25 & Lagos & $34.17 \pm 18.21$ & $22.85 \pm 22.15$ & $24.85 \pm 6.45$ & Adeoye et al. [86], Iridapo and Okwa [87] and Ajayi et al. [88] \\
\hline
\end{tabular}




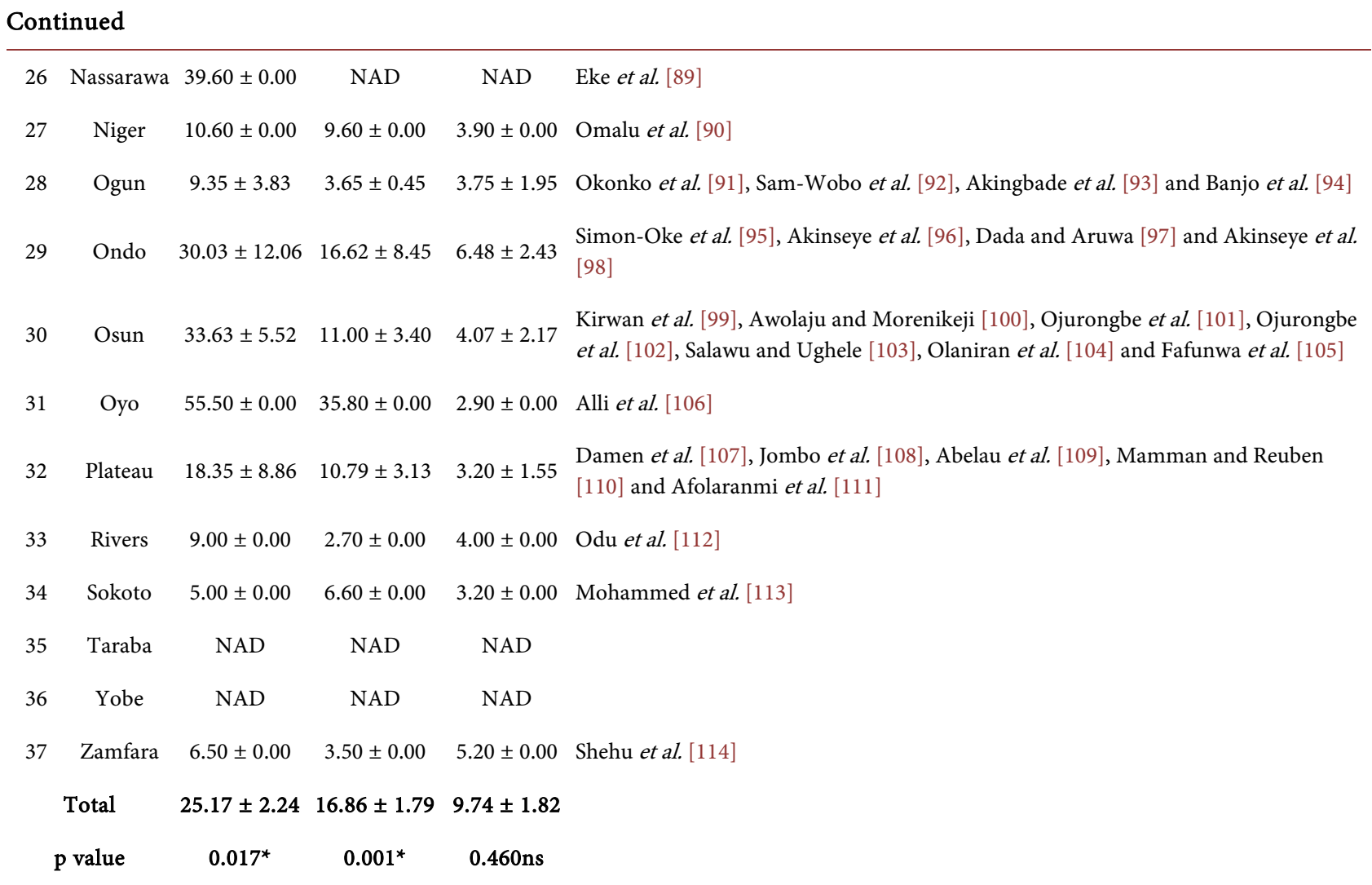

NAD: No Available Data, ${ }^{*}$-significant at $\mathrm{p} \leq 0.05$, ns: not significant at $\mathrm{p}>0.05$.

Kano (44.40\%). Meanwhile, it was observed that the prevalence of A. lumbricoides was high for states in Southern part of Nigeria. Zamfara, Sokoto, Borno Sates and the Federal Capital Territory (FCT), Abuja had low prevalence values of below $3.0 \%$ while 14 states in the country had prevalence of below $20.0 \%$.

For Hookworms, Akwa Ibom and Kano States had the highest average prevalence of $55.80 \%$ in the country. Delta, Oyo and Benue States had prevalence values of $38.08 \%, 35.80 \%$ and $35.40 \%$ respectively while 22 states in the country had prevalence of hookworm below 20.0\% with Rivers State having the least prevalence of $2.70 \%$.

T. trichiura which had the least average prevalence among the three STHs. Akwa Ibom State had the highest prevalence for this parasite with $40.40 \%$ followed by Lagos, Delta and Kwara States with prevalence values of $24.85 \%$, $24.05 \%$ and $23.37 \%$ respectively. Other states in the Federation had prevalence values of less than $12 \%$ with FCT, Abuja and Borno States having the least prevalence of $0.80 \%$ and $0.90 \%$ respectively.

\subsection{Predicted Risk of $A$, lumbricoides Infections}

The predicted high risk areas of $A$. lumbricoides infections were South-East and South-West region of Nigeria with probability of $\geq 0.75$. Also, all the states in Southern Nigeria, four states in North-Central Nigeria (Kwara, Kogi, Benue and Nassarawa States) with the FCT, Abuja are at risk of infections with probability 
of $\geq 0.50$. In North-West Nigeria, Kano and Katsina States are the two states that fall within the high risk areas. The prediction reveals that Nigeria was expected to have increased risk of infections with $A$. lumbricoides in comparison with the spatial distribution of infection where most areas fell within probability of $\geq 0.20$ (Figure 1).

\subsection{Model Performance and Influencing Factors}

The average percent contribution (PC) and permutation importance (PI) of the 20 variables used in the modeling of STH in this study were also assessed. In this study, precipitation of the wettest month had the highest PC and PI of 20.4 and 41 respectively, followed by altitude with PC of 15.2 and PI of 17 and precipitation of warmest quarter with PC of 10.8 and PI of 9.9. Also temperature seasonality was the fourth ranked model with PC of 8.2 and PI of 5.5. These four variables are among the five top variables in the modeling of STH in Nigeria. The other variables that performed well in the modeling were annual precipitation in PC and temperature seasonality in PI (Table 2).

The receiver operating characteristics (ROC) curve obtained as an average of the 10 replications runs is shown in Figure 2. Specificity was calculated. The

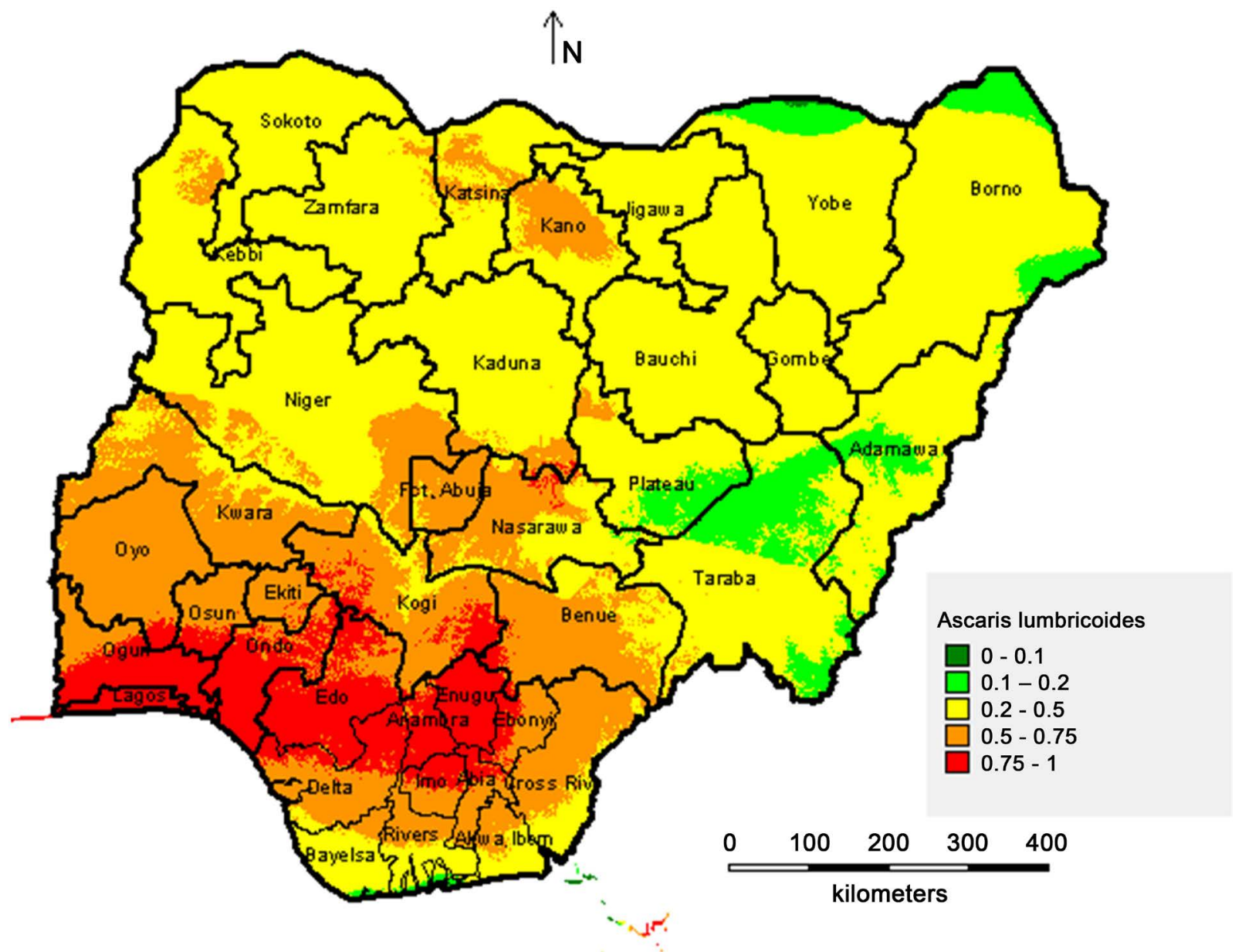

Figure 1. Predicted prevalence of Ascaris lumbricoides in Nigeria. 
Table 2. Average percent contribution (APC) and average permutation importance (API) of soil transmitted helminthes infection distribution models.

\begin{tabular}{|c|c|c|c|c|c|c|c|c|c|}
\hline \multirow{2}{*}{ Variable Type } & \multirow{2}{*}{ Variables } & \multicolumn{2}{|c|}{ Ascaris lumbricoides } & \multicolumn{2}{|c|}{ Hookworms } & \multicolumn{2}{|c|}{ Trichuris trichiura } & \multicolumn{2}{|c|}{ Top five models } \\
\hline & & PC & PI & PC & PI & PC & PI & PC & PI \\
\hline Elevation & Altitude & 2.5 & 2.6 & 9.7 & 7.3 & 33.3 & 41.2 & 15.2 & 17 \\
\hline \multirow[t]{11}{*}{ Temperature } & BIO1 & 0 & 0.2 & 0.6 & 1.5 & 0.3 & 0.7 & 0.3 & 0.8 \\
\hline & $\mathrm{BIO} 2$ & 4.8 & 18.5 & 3.4 & 13.8 & 0.8 & 3.8 & 3 & 12 \\
\hline & $\mathrm{BIO} 3$ & 0 & 0 & 0 & 0 & 0 & 0.2 & 0 & 0.1 \\
\hline & $\mathrm{BIO} 4$ & 17.6 & 12.9 & 5.6 & 2.9 & 1.3 & 0.8 & 8.2 & 5.5 \\
\hline & BIO5 & 0 & 0 & 0 & 0 & 0 & 0 & 0 & 0 \\
\hline & BIO6 & 15.3 & 0.9 & 19.4 & 0.2 & 13.4 & 0.1 & 16 & 0.4 \\
\hline & BIO7 & 0.2 & 0 & 0.1 & 0 & 0.3 & 0 & 0.2 & 0 \\
\hline & BIO8 & 0 & 0 & 0 & 0 & 0 & 0.4 & 0 & 0.1 \\
\hline & BIO9 & 0 & 0.8 & 0 & 0.1 & 0.1 & 2.2 & 0 & 1 \\
\hline & BIO10 & 0.2 & 0.6 & 1.7 & 2.2 & 0 & 0 & 0.6 & 0.9 \\
\hline & BIO11 & 4.1 & 2 & 1.4 & 1.1 & 3.2 & 5 & 2.9 & 2.7 \\
\hline \multirow[t]{8}{*}{ Precipitation } & BIO12 & 7.2 & 0.2 & 19.7 & 0.1 & 6.7 & 0 & 11.2 & 0.1 \\
\hline & BIO13 & 25.8 & 53.2 & 31 & 63.3 & 4.3 & 6.6 & 20.4 & 41 \\
\hline & BIO13 & 5.9 & 5.2 & 1.1 & 1.7 & 3 & 7.4 & 3.3 & 4.8 \\
\hline & BIO15 & 0 & 0 & 0.2 & 0 & 0.2 & 0 & 0.1 & 0 \\
\hline & BIO16 & 11.4 & 0.5 & 0.3 & 0 & 1.2 & 3.3 & 4.3 & 1.3 \\
\hline & BIO17 & 0.4 & 0.6 & 0.5 & 0.9 & 0.3 & 0 & 0.4 & 0.5 \\
\hline & BIO18 & 0.6 & 1.4 & 1.8 & 3 & 30 & 25.3 & 10.8 & 9.9 \\
\hline & BIO19 & 4 & 0.4 & 3.5 & 2 & 1.6 & 2.9 & 3 & 1.8 \\
\hline
\end{tabular}

PC: Percent Contribution, PI: Permutation Importance, Bolded: Five top models in terms of PC and PI, Elevation Variable: Altitude, Temperature Variables: BIO1, BIO2, BIO3, BIO4, BIO5, BIO6, BIO7, BIO8, BIO9, BIO10 and BIO11, Precipitation Variables: BIO12, BIO13, BIO14, BIO15, BIO16, BIO17, BIO18 and BIO19.

average and standard deviation of the area under the curve (AUC) for the 10 replicate runs was $0.940 \pm 0.028,0.948 \pm 0.017$ and $0.948 \pm 0.021$ for A. lumbricoides, Hookworms and T. trichiura respectively. These values show an excellent performance of the modeling software as an AUC value of greater than 0.80 shows higher sensitivity and specificity for the presence of these parasites.

The relative importance of each variable to the prevalence of $A$. lumbricoides was assessed with the jackknife test in Figure 3 which gave a total training gain of 1.7 (red bar) and an area under the curve (AUC) value of 0.94 (red bar). The jackknife test indicated that precipitation of wettest month and temperature seasonality are the two variables when used alone will affect the prevalence of $A$. lumbricoides the most. Meanwhile, no variable was observed to significant decrease the gain the most. The jackknife test indicated that precipitation of the wettest month and temperature seasonality are more informative when used in 
(a) Average Sensitivity vs. 1 - Specificity for Ascaris_lumbricoides

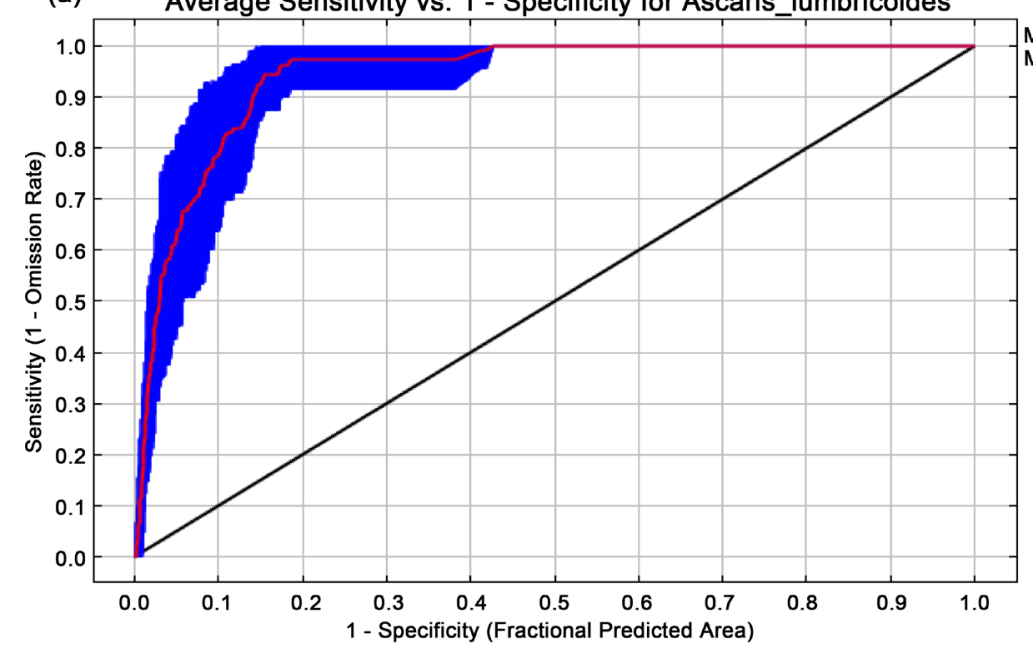

Mean (AUC $=0.940$ ) Mean +l- one stddev Random Prediction -

(b) Average Sensitivity vs. 1 - Specificity for Hookworms

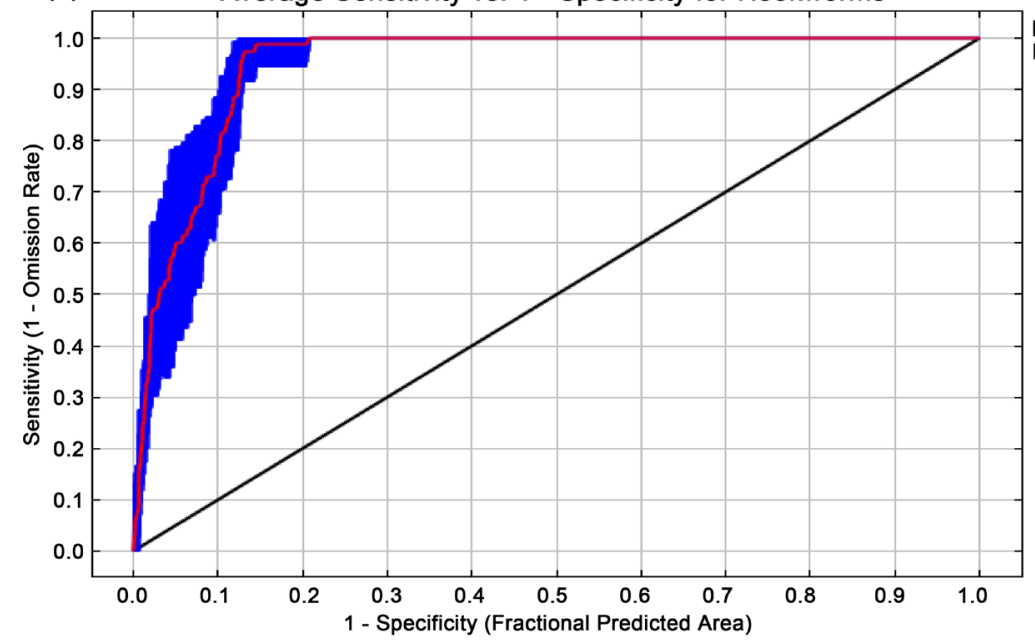

Mean (AUC $=0.948)$ Mean $+/$ - one stddev Random Prediction

(c) Average Sensitivity vs. 1 - Specificity for Trichuris_trichiura

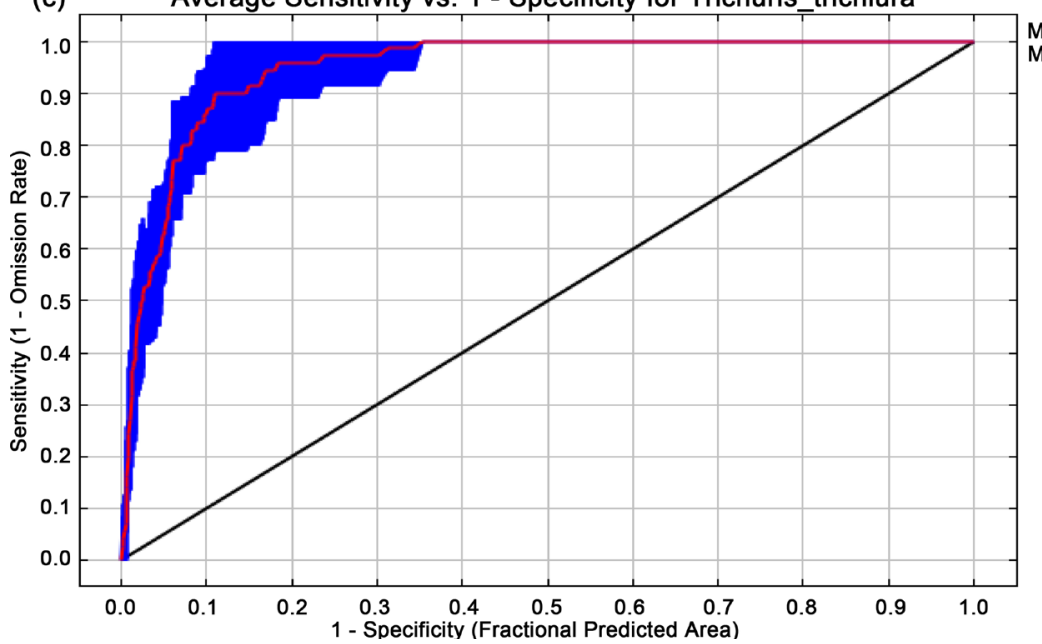

Mean $(A \cup C=0.948)$ Mean $+/$ - one stddev Random Prediction -

(a) Average AUC $=(0.964,0.909,0.928,0.967,0.903,0.938,0.965,0.913,0.965$ and 0.948$)$ divided by 10. (b) Average AUC $=(0.969,0.936,0.935$, $0.918,0.947,0.938,0.968,0.948,0.944$ and 0.974$)$ divided by 10. (c) Average AUC $=(0.928,0.905,0.964,0.930,0.972,0.963,0.938,0.959,0.964$ and 0.960 ) divided by 10 .

Figure 2. Area under the Curve (AUC) (a) Ascaris lumbricoides (b) Hookworms (c) Trichuris trichiura. Red line indicates the mean value for 10 MaxEnt replicate runs and blue indicates the standard deviation. 


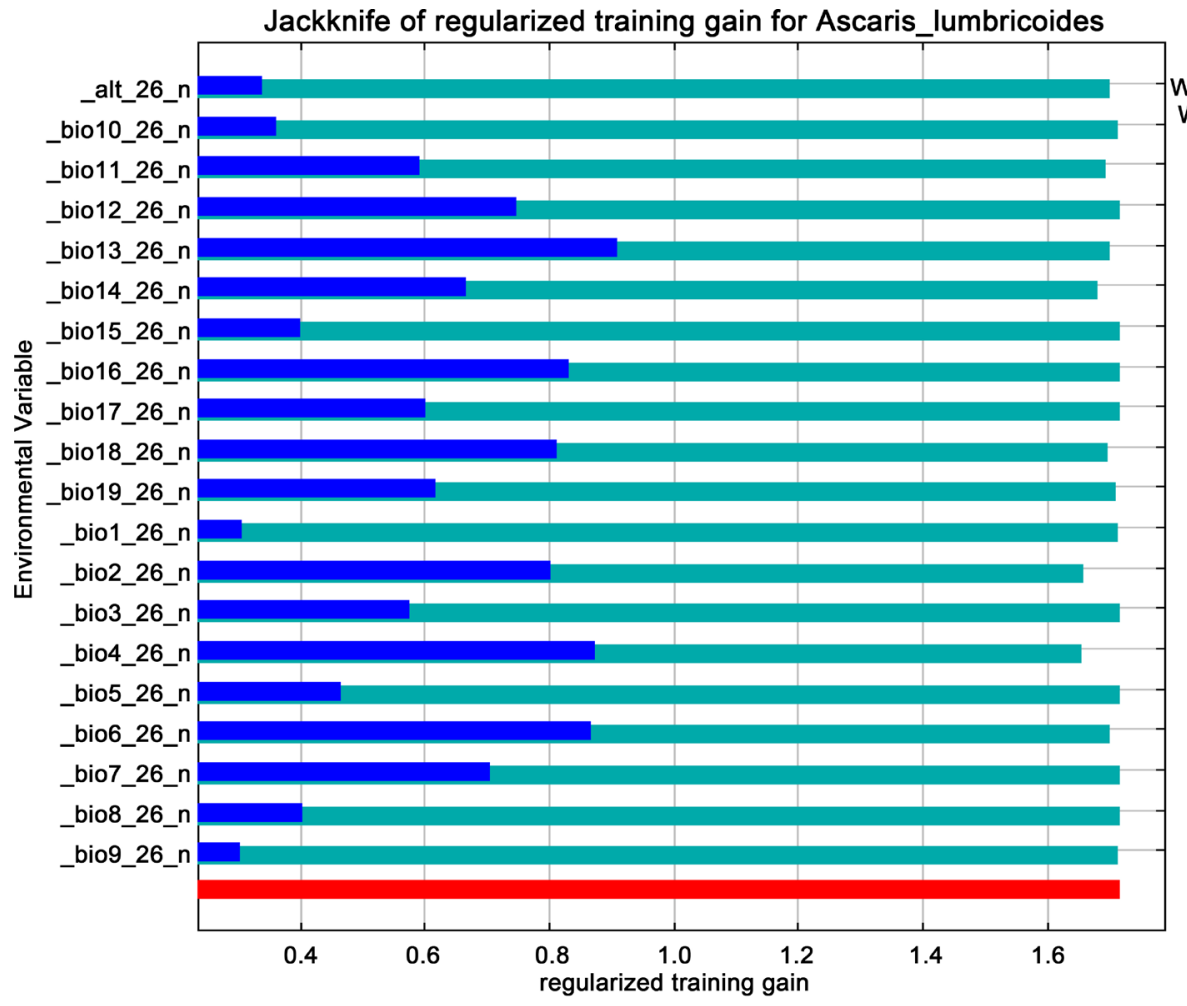

Without variable = With only variable With all variables =

(a)

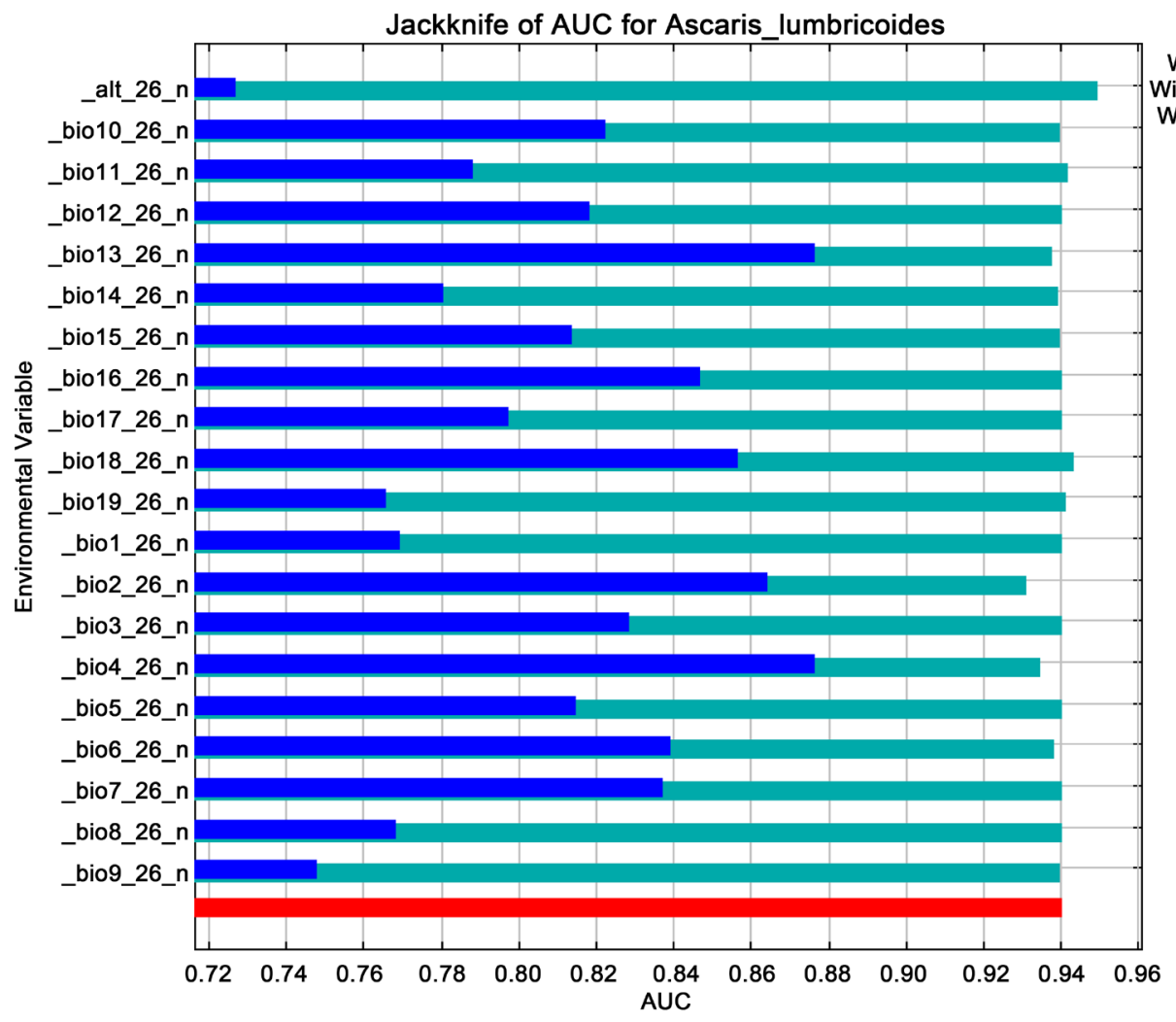

Without variable With only variable = With all variables

(b)

Figure 3. Ascaris lumbricoides Jacknife Analysis (a) training gain and (b) AUC. The dark blue, light blue and red bars represent results of the model with each individual variable, all the remaining variables and all variables respectively. 
predicting prevalence for this $A$. lumbricoides.

For hookworms, a total training gain of 1.86 and an AUC value of 0.948 (red bars) was observed (Figure 4). Also, precipitation of the wettest month had the highest training gain of 1.26 and an AUC value of 0.889 when used alone. This variable is therefore considered the most informative in predicting the prevalence of hookworms.

The variable assessment for $T$. trichiura was observed to be different from the other parasites. A total training gain of 1.96 and an AUC value of 0.95 were observed with minimum temperature of the coldest month having the highest impact on the prevalence of this parasite when used alone with a training gain of 1.3 followed by precipitation of the wettest month and altitude with training gain of 1.1 both. For the AUC values, altitude was highest with 0.906 followed by precipitation of the wettest month and minimum temperature of the coldest month with AUC values of 0.892 and 0.882 respectively (Figure 5).

The modeling result of STH in Nigeria revealed that most of the areas at high risk of infections were the states in the South-East (Anambra, Enugu, Imo, Abia and Ebonyi), South-South (Edo, Rivers, Delta, Cross-River, Akwa-Ibom and Bayelsa) and some states in the South-West (Lagos, Ogun and Ondo) and North Central (Benue and Kogi) and few states in the extreme northern part of the country such as Kebbi and Niger and parts of Taraba and Adamawa States. These areas are observed to have high precipitation throughout the year and were mostly in locations of low altitude. Kebbi, Niger and Taraba States fell within the high risk region, despite their low precipitation and high altitude when compared to the southern region.

\subsection{Predicted Risk of Hookworms Infections}

The five states in South-East Nigeria (Enugu, Imo, Owerri, Ebonyi and Anambra), Edo and Delta States in South-South Nigeria and Lagos and Ogun States in South-West Nigeria are in the high risk areas of hookworm infections with probability of $\geq 0.75$. Also, all the states in South-South, South-East, four states in the South-West (Lagos, Ogun, Ondo and part of Osun) and part of some states in North-Central (Kogi, Benue, Nasarawa, Niger and FCT) were within areas with risk of probability of $\geq 0.50$. Some states in Northern Nigeria fall within the low risk areas. Part of Kebbi, Sokoto, Plateau, Taraba, Jigawa, Yobe and Borno States with probability of 0.00 to $\leq 0.10$ (Figure 6).

\subsection{Predicted Risk of T. trichiura Infections}

Risk of infection with T. trichiura was lower as compared to A. lumbricoides and Hookworms. Although, some states in Nigeria were expected to experience high risk of infections; South-West (Lagos, Ogun, Ondo and part of Osun), all the states in the South-South and South-East Nigeria and parts of Benue, Kogi, Niger, Kebbi, Plateau, Taraba, Adamawa, Gombe, Bauchi and Maiduguri were within risk of $\geq 0.50$. Kaduna and Katsina states fall within the low risk areas (Figure 7). 


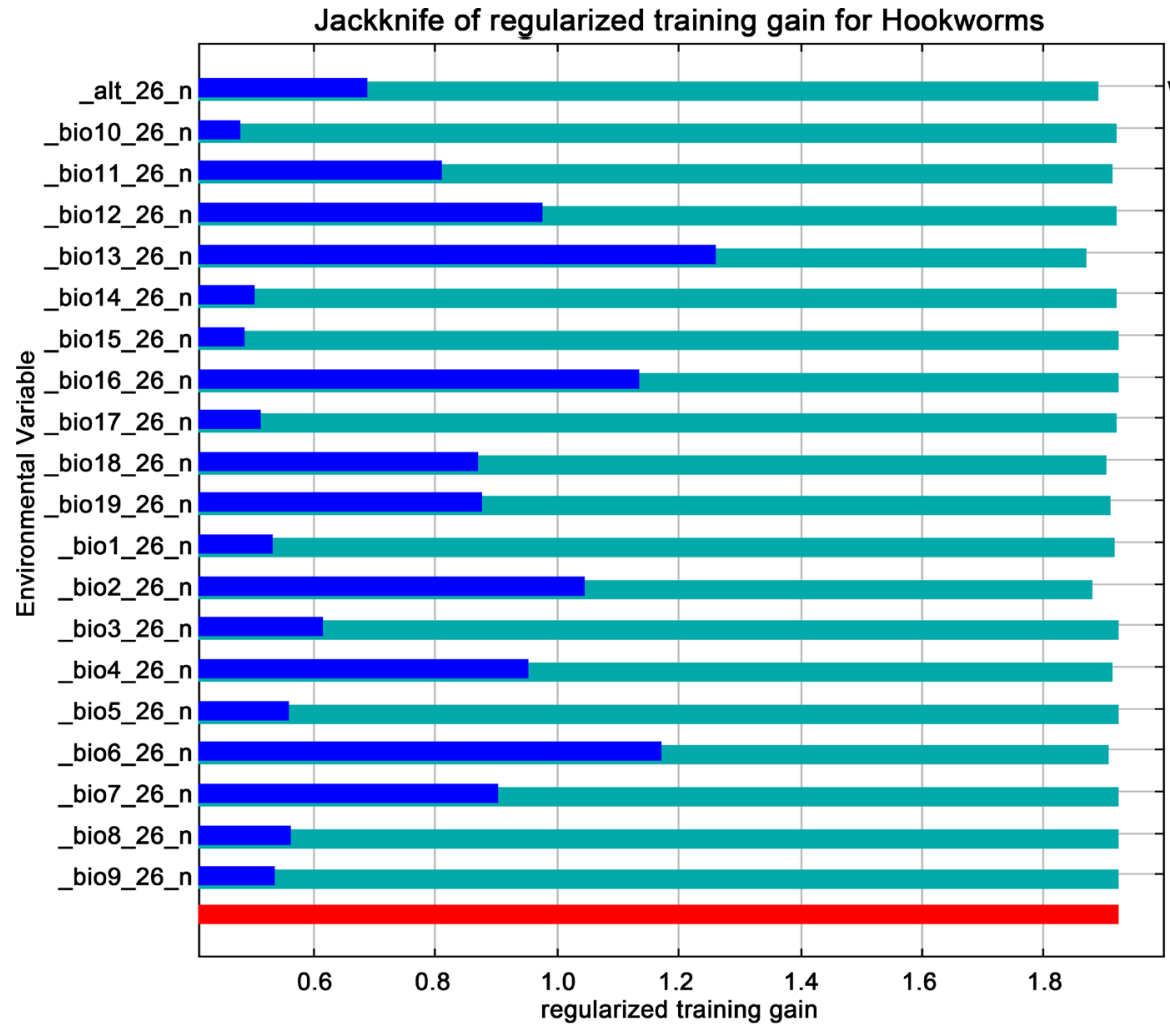

(a)
Without variable With only variable $\mathbf{0}$ With all variables

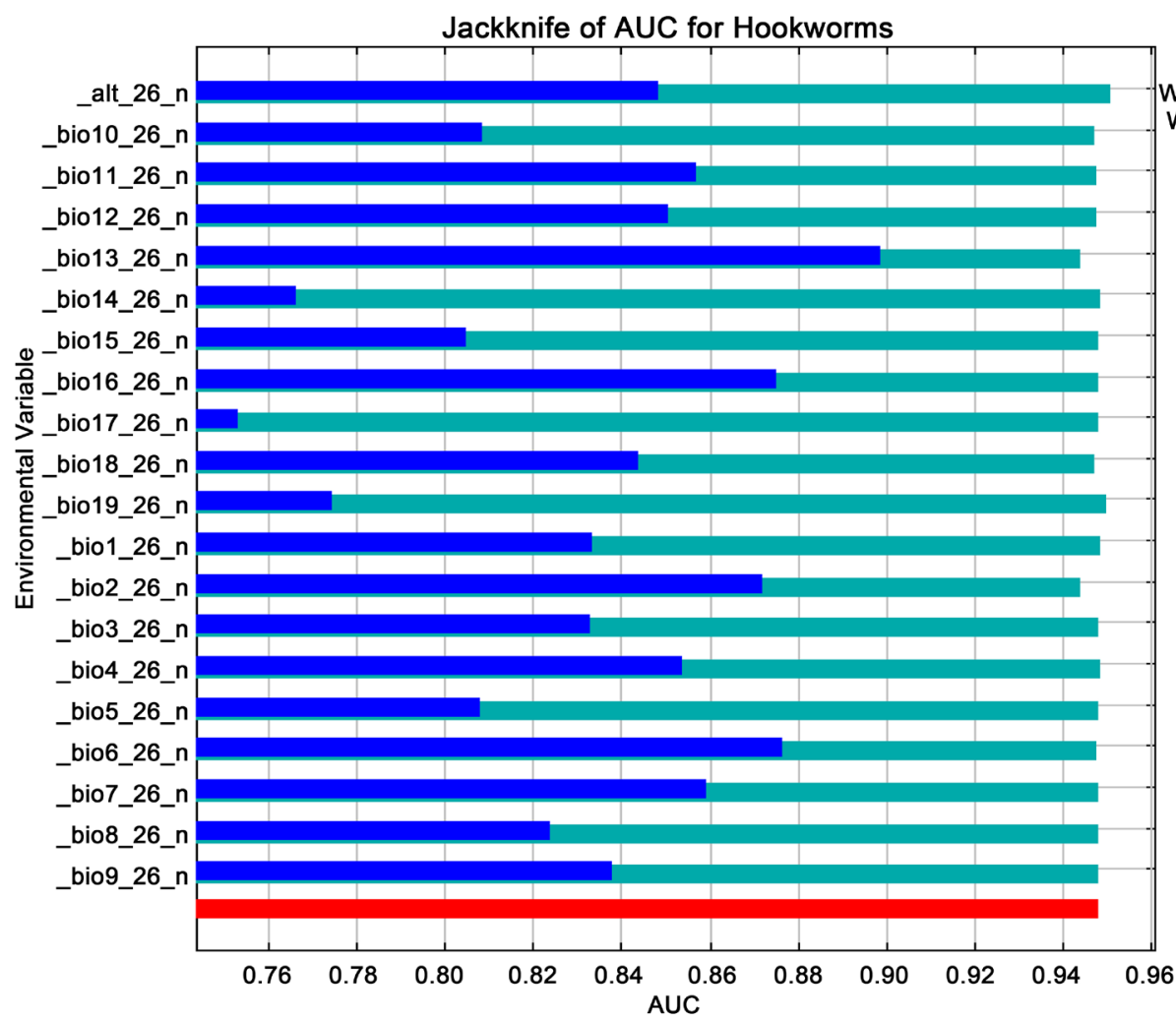

Without variable With only variable With all variables =

(b)

Figure 4. Hookworms Jacknife Analysis (a) training gain and (b) AUC. The dark blue, light blue and red bars represent results of the model with each individual variable, all the remaining variables and all variables respectively. 


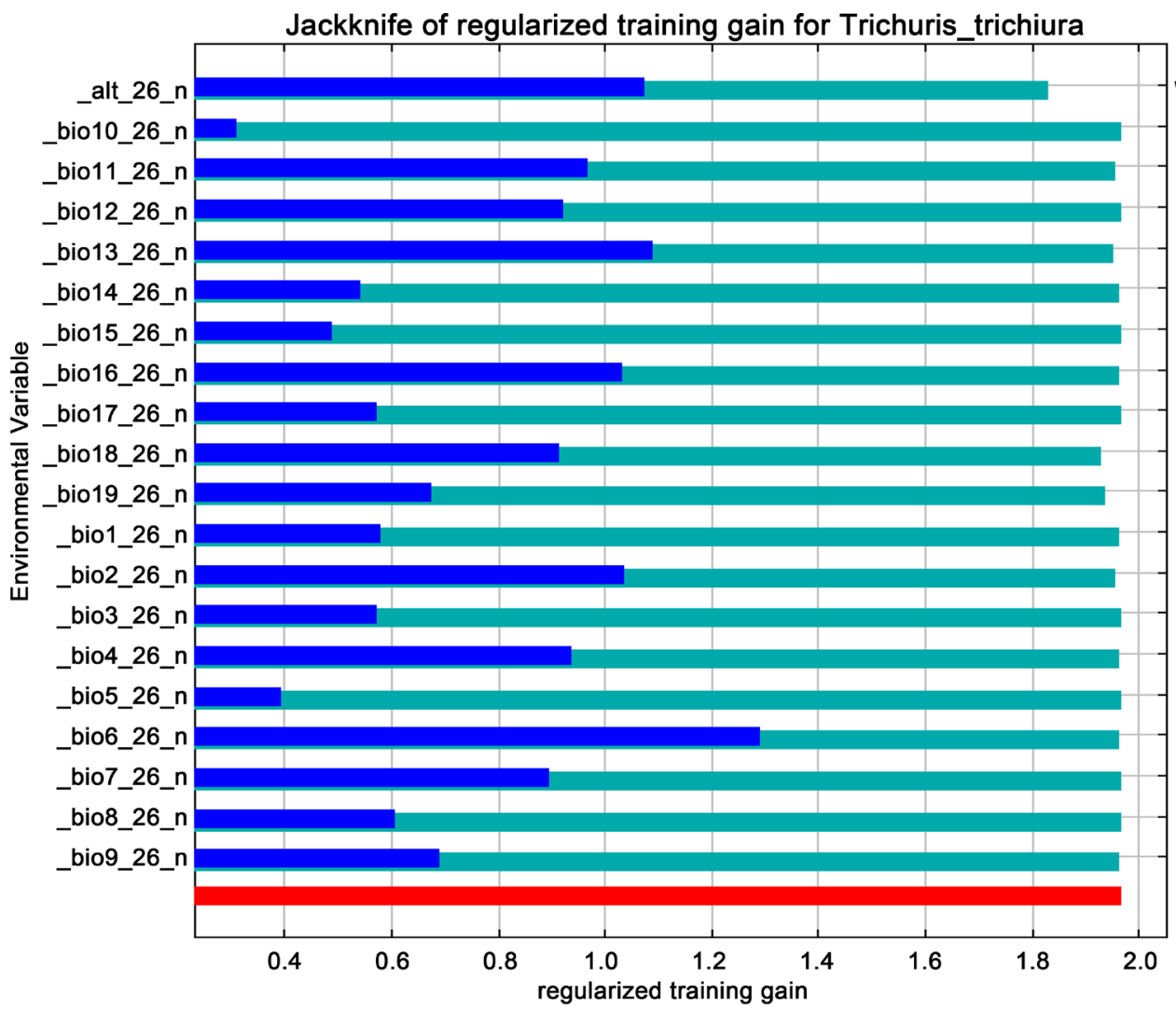

Without variable With only variable With all variables

(a)

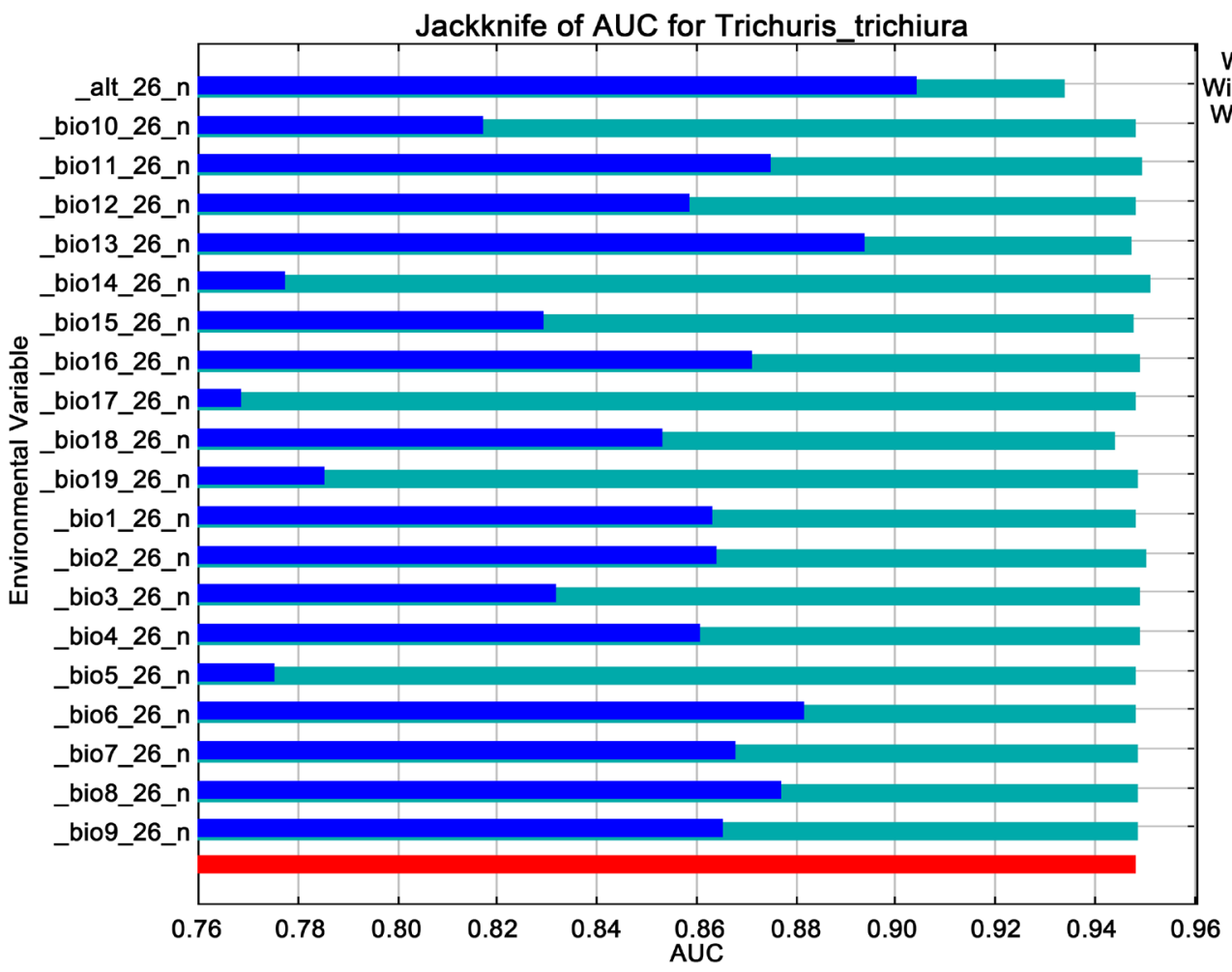

Without variable $=$ With only variable With all variables =

(b)

Figure 5. Trichuris trichiura Jacknife Analysis (a) training gain and (b) AUC. The dark blue, light blue and red bars represent results of the model with each individual variable, all the remaining variables and all variables respectively. 


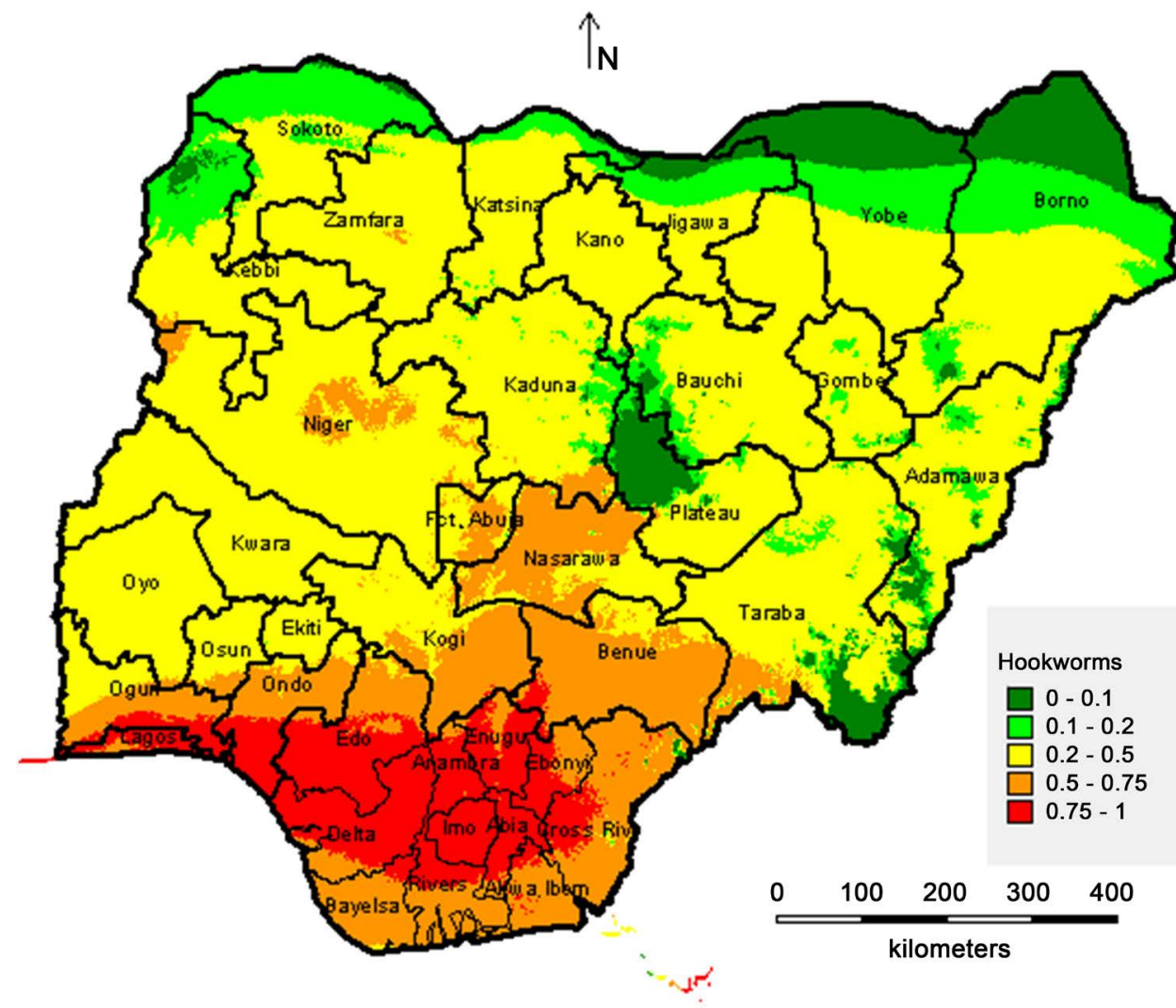

Figure 6. Predicted prevalence of Hookworms in Nigeria.

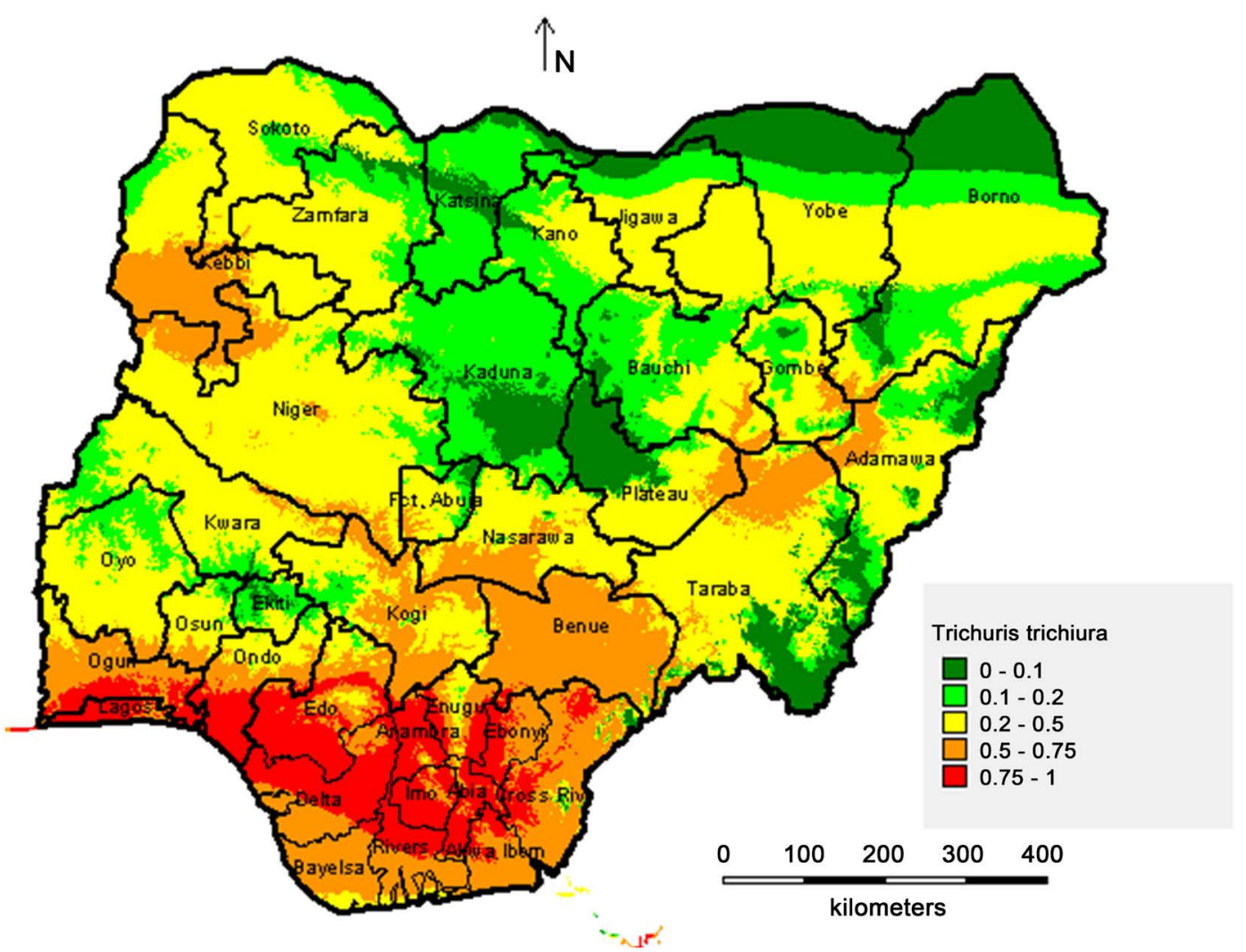

Figure 7. Predicted prevalence of Trichuris trichiura in Nigeria. 


\section{Discussion}

Most regions in Nigeria were characterized by varying prevalence of STHs. This study revealed that all states in Nigeria were endemic for STHs with some regions at higher risk than others. The high prevalence of STHs in Southern Nigeria observed in this study was due to the favorable environmental conditions such as high level of precipitation and the low altitude of these regions [115]. Altitude was inversely proportional to the prevalence of STH infections. That is, the lower the altitude, the higher the prevalence of STH infections. On the other hand, temperature and precipitation were directly proportional to the prevalence of STH infections. This explains the high prevalence and risk in the Southern region. The reverse situation observed in Kebbi, Niger and Taraba States with high risk of infection with STHs despite low precipitation and high altitude which could be due to the presence of man-made lakes that run through several communities providing the required humidity for STHs transmission. This trend was same in Kano State only in the case of A. Lumbricoides which may be due to other prevailing factors such as population density and human behavior. Awolaju and Morenikeji [100] and Ojurongbe et al. [116] stated that other factors such as socio-economic status, unhygienic practices, ignorance and poverty are among the factors contributing to the high prevalence of STHs in this region. Ugbomoiko et al. [117] reported that the use of leaves and paper to clean up after defecation and the act of geophagy are attitudes common in Southern Nigeria and North-Central Nigeria and this might also contribute the high level of infection.

Other factors that are responsible for STHs infection generally in Nigeria are lack of and inadequate toilet facilities leading to open defecation in most communities, poor personal hygiene and improper environmental sanitation, behavior of individuals such as biting of fingernails, walking barefoot [115], drinking of contaminated water and low socio-economic status of the populace.

From the spatial distribution of STHs, most communities in Nigeria were characterized with prevalence below $20 \%$. Similar observation was reported by Oluwole et al. [79] who stated that the overall low infection of $20 \%$ could be due to the periodic deworming of school-aged children. Although, the risk prediction shows that increase in prevalence of these parasites was expected in areas presently having prevalence of below $20 \%$. The results obtained using 20 environmental variables revealed that precipitation of the wettest month; altitude and minimum temperature of the coldest month were the three major environmental variables that determine the distribution of these parasites in Nigeria. Similar observation was noted in the studies of Otto [118], Spindler [119] and Oluwole et al. [79], they stated that high humidity promotes quick embryonation of $A$. lumbricoides eggs. Studies by Chammartin et al. [120] and Lai et al. [121] in Bolivia and China respectively also reports the influence of temperature on the distribution of STHs. Oluwole et al. [79] states that the low predicted risk in Northern Nigeria could be due to the extreme heat and short wet season. High 
altitude which was among the top variable in the determinant of infections was observed to significantly contribute to the low risk areas in Northern Nigeria than Southern Nigeria as this region was located on high altitude. Communities located at high altitude also experience low or no influx of parasitic contaminants.

In this present study, A. lumbricoides was observed to have the widest spatial and potential distribution in Nigeria with many areas at risk compared to hookworms and T. trichiura. This was similar to what was observed by Pullan et al. [122] in Kenya, Chammartin et al. [120] in Bolivia, Lai et al. [121] in China.

\section{Conclusion}

Nigeria is endemic for the A. lumbricoides, hookworms and Trichuris trichiura with an average prevalence of $25.17 \%, 16.86 \%$ and $9.74 \%$ respectively. Precipitation of the wettest month, altitude, precipitation of the warmest quarter, temperature seasonality and annual precipitation are the five environmental variables that majorly affect the distribution of soil transmitted helminth infections in Nigeria. Southern Nigeria has high prevalence of soil transmitted helminth infections than Northern Nigeria.

\section{Recommendations}

The model generated will help to guide individuals in the high risk areas to take preventive and curative measures. The finding also provides us with the scientific understanding of the effect of precipitation, temperature and altitude on the distribution of STHs. Based on this knowledge, planning and control of STHs in Nigeria will yield greater result with the limited funding and human resources available.

\section{Acknowledgements}

The authors appreciate the Center for Information and Communication Technology, Kogi State University, Anyigba, Nigeria for providing an enabling environment for the analysis to be conducted.

\section{Conflict of Interest}

The authors have declared that no competing interest exists.

\section{Authors Contribution}

EK conceived the study, CAY extracted data and carried out statistical analysis. EK, CAY and SAL developed the manuscript, read and approved the final manuscript.

\section{Significance Statement}

This study discovers the areas of high risk for soil transmitted helminths infections in Nigeria as well as identifying environmental variables that majorly de- 
termine the distribution of these parasites. This study will help researchers, policy makers in the health sector and other relevant authorities to intensify control strategies in areas of high risk of infections. It reveals that increasing altitude leads to decreased prevalence and increasing temperature and precipitation lead to increased prevalence.

\section{References}

[1] Finkelstein, J.L., Schleinitz, M.D., Carabin, H. and McGarvey, S.T. (2008) Decision-Model Estimation of the Age-Specific Disability Weight for Schistosomiasis Japonica: A Systematic Review of the Literature. PLOS Neglected Tropical Diseases, 2, e158. https://doi.org/10.1371/journal.pntd.0000158

[2] Federal Ministry of Health (FMoH) (2012) Nigeria Master Plan for Neglected Tropical Diseases (NTDs) 2013-2017.

[3] Bethony, J., Brooker, S., Albonico, M., Geiger, S.M., Loukas, A., Diemert, D. and Hotez, P.J. (2006) Soil Transmitted Helminth Infections: Ascariasis, Trichuriasis, and Hookworm. The Lancet, 367, 1521-1532. https://doi.org/10.1016/S0140-6736(06)68653-4

[4] Hotez, P.J., Asojo, O.A. and Adesina, A.M. (2012) Nigeria: "Ground Zero" for the High Prevalence Neglected Tropical Diseases. PLoS Neglected Tropical Diseases, 6, e1600. https://doi.org/10.1371/journal.pntd.0001600

[5] Oluwole, A.S., Ekpo, U.F., Karagiannis-Voules, D.A., Abe, E.M., Olamiju, F.O., Isiyaku, S., Okoronkwo, C., Saka, Y., Nebe, O.J., Braide, E.I., Mafiana, C.F., Utzinger, J. and Vounatsou, P. (2015) Bayesian Geostatistical Model-Based Estimates of Soil Transmitted Helminth Infection in Nigeria, Including Annual Deworming Requirements. PLOS Neglected Tropical Diseases, 9, e0003740.

https://doi.org/10.1371/journal.pntd.0003740

[6] Grantham-McGregor, S. and Ani, C.A. (2001) Review of Studies on the Effect of Iron Deficiency on Cognitive Development in Children. Journal of Nutrition, 131, 649S-666S. https://doi.org/10.1093/jn/131.2.649S

[7] Ezeamama, A.E., Friedman, J.F., Acosta, L.P., Bellinger, D.C., Langdon, G.C., Manalo, D.L., et al. (2005) Helminth Infection and Cognitive Impairment among Filipino Children. American Journal of Tropical Medicine and Hygiene, 72, 540-548.

[8] Malone, J.B. (2005) Biology-Based Mapping of Vectorborne Parasites by Geographic Information Systems and Remote Sensing. Parassitologia, 47, 27-50.

[9] Peterson, A.T. and Shaw, J. (2003) Lutzomyia Vectors for Cutaneous Leishmaniasis in Southern Brazil: Ecological Niche Models, Predicted Geographic Distribution, and Climate Change Effects. International Journal for Parasitology, 33, 919-931. https://doi.org/10.1016/S0020-7519(03)00094-8

[10] Karagiannis-Voules, D.A., Biedermann, P., Ekpo, U.F., Garba, A., Langer, E., Mathieu, E., Midzi, N., Mwinzi, P., Polderman, A.M. and Raso, G. (2015) Spatial and Temporal Distribution of Soil-Transmitted Helminth Infection in Sub-Saharan Africa: A Systematic Review and Geostatistical Meta-Analysis. The Lancet, Infectious Diseases, 15, 74-84. https://doi.org/10.1016/S1473-3099(14)71004-7

[11] Phillips, S.J., Anderson, R.P. and Schapire, R.E. (2006) Maximum Entropy Modeling of Species Geographic Distributions. Ecological Modelling, 190, 231-259. https://doi.org/10.1016/j.ecolmodel.2005.03.026

[12] Anderson, R.P., Lew, D. and Peterson, A.T. (2003) Evaluating Predictive Models of Species' Distributions: Criteria for Selecting Optimal Models. Ecological Modelling, 
162, 211-232. https://doi.org/10.1016/S0304-3800(02)00349-6

[13] Graham, C.H., Ferrier, S., Huettman, F., Moritz, C. and Peterson, A.T. (2004) New Developments in Museum-Based Informatics and Applications in Biodiversity Analysis. Trends in Ecology and Evolution, 19, 497-503. https://doi.org/10.1016/j.tree.2004.07.006

[14] Phillips, S.J., Dudik, M. and Schapire, R.E. (2004) A Maximum Entropy Approach to Species Distribution Modelling. 21st International Conference on Machine Learning, Banff, 83. https://doi.org/10.1145/1015330.1015412

[15] Phillips, S.J. and Dudík, M. (2008) Modeling of Species Distributions with MaxEnt: New Extensions and a Comprehensive Evaluation. Ecography, 31, 161-175. https://doi.org/10.1111/j.0906-7590.2008.5203.x

[16] Sarma, R.R., Munsi, M. and Ananthram, A.N. (2015) Effect of Climate Change on Invasion Risk of Giant African Snail (Achatina fulica Ferussac 1821: Achatinidae) in India. PLoS ONE, 10, e0143724. https://doi.org/10.1371/journal.pone.0143724

[17] Elith, J., Graham, C.A., Dudık, M., Ferrier, S., Guisan, A., Hijmans, R., et al. (2006) Novel Methods Improve Prediction of Species' Distributions from Occurrence Data. Ecogeography, 29, 129-151. https://doi.org/10.1111/j.2006.0906-7590.04596.x

[18] Peterson, A.T., Soberon, J., Pearson, R.G., Anderson, R.P., Martınez-Meyer, E., Nakamura, M. and Bastos, M. (2011) Ecological Niches and Geographic Distributions. Princeton University Press, Princeton.

[19] Nduka, F.O., Etusim, P.E., Nwaugo, V.O. and Oguariri, R.M. (2006) The Effects of Quarry Mining on the Epidemiolog y of Schistosoma haematobium in Schoolchildren, in Ishiagu, Southeastern Nigeria. Annals of Tropical Medical Parasitology, 100, 155-161. https://doi.org/10.1179/136485906x78544

[20] Wosu, M.I. and Onyeabor, A.I. (2014) The Prevalence of Intestinal Parasite Infections among School Children in a Tropical Rainforest Community of Southeastern Nigeria. Journal of Animal Science Advances, 4, 1004-1008. https://doi.org/10.5455/jasa.20140827111807

[21] Kalu, M.K. and Ihemanma, C.A. (2014) Prevalence of Parasitic Helminthes in Stools of Children Aged 4 - 12 Years in AhabaImenyi Community of Abia State, Nigeria. Sci-Agric Journal of Scientific Issues, Research and Essay, 2, 124-127.

[22] Ihemanma, C.A. and Oladele, O.T. (2015) Prevalence of Intestinal Parasites and Associated Risk Factors among School Children (5-16 Years) in Ihite-Ude, Ofeme Community in Umuahia North L.G.A, Abia State. International Journal of Research and Review, 2, 732-738.

[23] Ezeigbo, O.R. and Ezeigbo, I.C. (2016) Malaria and Soil Transmitted Helminthes Co-Infection among Abia State Polytechnic Students, Aba, South Eastern Nigeria. International Invention Journal of Medicine and Medical Sciences, 3, 68-71.

[24] Naphtali, R., Ayuba, K. and Zabiri, J.M. (2016) Epidemiological and Environment Studies on Intestinal Helminthes among Dwellers of Hauseri 1 Ward, Michika Local Government Area of Adamawa State, Nigeria. International Journal of Innovative Research and Development, 5, 192-196.

[25] Enimien, O.J., Fana, S.A. and Emmanuel, W.B. (2014) Intestinal Helminthic Infection in Numan (Northeast Nigeria). International Journal of Innovation and Applied Studies, 5, 102-105.

[26] Houmsou, R.S., Elkanah, S.O., Garba, L.C., Wama, B.E., Amuta, E.U. and Kela, S.L. (2015) Spatial Distribution of Soil-Transmitted Helminthiases and Co-Infection with Schistosomiasis among School Children in Nigeria. Asian Pacific Journal of Tropical Medicine, 5, 779-785. https://doi.org/10.1016/S2222-1808(15)60930-6 
[27] Oriakpono, J.E., Sani, A.F. and Wama, B.E. (2015) Intestinal Helminthic Infection in Numan (Northeast Nigeria). International Journal of Progressive Sciences and Technologies, 1, 1-4.

[28] Naphtali, R.S., Birdling, Y.M. and Philimon, B. (2017) Studies on Intestinal Helminthes Infection in Rumde Nursery and Primary School Pupils, in Jimeta, Adamawa State, Nigeria. IOSR Journal of Nursing and Health Science, 6, 45-47. https://doi.org/10.9790/1959-0601024547

[29] Opara, K.N., Udoidung, N.I., Opara, D.C., Okon, O.E., Edosomwan, E.U. and Udoh, A.J. (2012) The Impact of Intestinal Parasitic Infections on the Nutritional Status of Rural and Urban School-Aged Children in Nigeria. International Journal of $M C H$ and AIDS, 1, 73-82. https://doi.org/10.21106/ijma.8

[30] Usip, L.P.E. and David, N.C. (2013) The Prevalence of Human Intestinal Helminths and the Efficacy of Antihelmintic Levamisole Drug in Abak Local Government Area of Akwa Ibom State Nigeria. Basic Research Journal of Medicine and Clinical Sciences, 2, 52-58.

[31] Usip, L.P.E. and Matthew, E.E. (2015) The Prevalence of Intestinal Helminthes and Efficacy of Anthelmintic (Pyrantel) Drugs among Primary School Children in Obot Akara Local Government Area, Akwa Ibom State, Nigeria. Peak Journal of Public Health and Management, 3, 46-55.

[32] Chukwuma, M.C., Ekejindu, I.M., Agbakoba, N.R., Ezeagwuna, D.A., Anaghalu, I.C. and Nwosu, D.C. (2009) The Prevalence and Risk Factors of Geohelminth Infections among Primary School Children in Ebenebe Town, Anambra State, Nigeria. Middle-East Journal of Scientific Research, 4, 211-215.

[33] Ogbuagu, C.N., Eneanya, C.I., Chukwuma, C., Ogbuagu, E.N. and Oguoma, V.M. (2009) High Prevalence of Intestinal Parasites in a Nigerian Tertiary Health Institution. The Internet Journal of Parasitic Diseases, 4, 1-7.

[34] Ezeagwuna, D.A., Okwelogu, I.S., Ekejindu, I.M. and Ogbuagu, C.N. (2009) The Prevalence and Socio-Economic Factors of Intestinal Helminth Infections among Primary School Pupils in Ozubulu, Anambra State, Nigeria. The Internet Journal of Epidemiology, 9, 1-5.

[35] Emmy-Egbe, I.O. (2013) Faecal Disposition Methods and Incidence of Intestinal Helminth Parasites among School Children in Ihiala Local Governmnet Area, Anambra State, Nigeria. International Science Research Journal, 81-87.

[36] Chioma, U., Mbanugo, J.I. and Nwachukwu, E. (2015) Prevalence of Intestinal Helminthes Parasite in Stools of Nursery and Primary Schools Pupils in Uga, Anambra State, Nigeria. Sky Journal of Microbiology Research, 3, 6-10.

[37] Agi, P.I. and Awi-Waadu, G.D.B. (2008) Hookworm Infection in Amassoma Community in the Niger Delta, Nigeria. Journal of Applied Sciences and Environmental Management, 12, 17-20.

[38] Bariweni, P.A., Ekweozor, I.K.E. and Bassey, S.E. (2009) The Epidemiology and Distribution of Non-Zoonotic Soil-Transmitted-Helminths in the Yenagoa Metropolis, Niger Delta, Nigeria. African Journal of Environmental Pollution and Health, 7, 1-6.

[39] Bariweni, P.A., Ekweozor, I.K.E. and Ogbonna, D.N. (2014) Assessment of Nonzoonotic Soil-Transmitted Helminth Levels in Soils in Yenagoa Metropolis, Niger Delta. Journal of Environmental Health, 76, 108-112.

[40] Tyoalumun, K., Abubakar, S. and Christopher, N. (2016) Prevalence of Intestinal Parasitic Infections and Their Association with Nutritional Status of Rural and Urban Pre-School Children in Benue State, Nigeria. International Journal of MCH and 
AIDS, 5, 146-152.

[41] Biu, A.A., Kofur, I. and Mohammed, A. (2013) Prevalence of Human Gastro-Intestinal Parasites in Biu, Borno State, Nigeria. Journal of Biological Science and Bioconservation, 5, 8-12.

[42] Biu, A.A., Kyari, F. and John, W.M. (2012) Prevalence of Intestinal Parasites in School Aged Pupils in Mafa Local Government Area of Borno State, Nigeria. Journal of Medical and Applied Biosciences, 4, 54-58.

[43] Usip, L.P.E. and Ita, A.E. (2017) Comparative Prevalence of Intestinal Parasites among Children in Public and Private Schools in Calabar South, Calabar, Cross River State, Nigeria. American Journal of Research Communication, 5, 80-97.

[44] Egwunyenga, O.A. and Ataikiru, D.P. (2005) Soil-Transmitted Helminthiasis among School Age Children in Ethiope East Local Government Area, Delta State, Nigeria. African Journal of Biotechnology, 4, 938-941.

[45] Nmorsi, O.P.G., Isaac, C., Aashikpelokhai, I.S. and Ukwandu, N.C.D. (2009) Geohelminthiasis among Nigerian Pre-School Age Children. Bangladesh Journal of Scientific and Industrial Resources, 44, 399-411.

[46] Prosper, O., Ibidapo, C.A. and Okwa, O.O. (2014) Prevalence and Risk Factors of Geohelminthiasis in Umuebu Community, Ukwuani Local Government Area, Delta State, Southern Nigeria. British Journal of Medicine and Medical Research, 4, 1175-1186. https://doi.org/10.9734/BJMMR/2014/6879

[47] Ito, E.E. and Egwunyenga, A.O. (2017) Soil-Transmitted Helminthiasis in Aviara Community: An Observation from Primary School Children in Nigeria. International Medical Journal, 24, 205-208.

[48] Uneke, C.J., Eze, O.K., Oyibo, P.G., Azu, N.C. and Ali, E. (2006) Soil-Transmitted Helminths Infection in School Children in South-Eastern Nigeria: The Public Health Implication. The Internet Journal of Third World Medicine, 4, 1-7.

[49] Ivoke, N. (2007) A Coprological Survey of Geohelminth Infections among School Children in Rural Ebonyi State, Nigeria. Animal Research International, 4, 653-661.

[50] Alo, M., Ugah, U. and Elom, M. (2013) Prevalence of Intestinal Parasites from the Fingers of School Children in Ohaozara, Ebonyi State, Nigeria. American Journal of Biological, Chemical and Pharmaceutical Sciences, 1, 22-27.

[51] Dimejesi, I.B.O., Umeora, O.U.J. and Egwuatu, C.E. (2017) Prevalence and Pattern of Soil-Transmitted Helminthiasis among Pregnant Women in a Tertiary Health Facility, Southeast Nigeria. African Journal of Medical and Health Sciences, 13, 56-61. https://doi.org/10.4103/2384-5589.139445

[52] Ivoke, N., Ivoke, O.N., Odii, E.C., Ekeh, F.N., Odo, G.E. and Asogwa, C.N. (2014) Prevalence and Risk Factors for Intestinal Nematode Infections in Children as Environmental Health Indicators for Prevention in Sub-Saharan Tropical Communities of Ebonyi State, Nigeria. Animal Research International, 11, 1840-1850.

[53] Okeke, O.C. and Ubachukwu, P.O. (2015) A Cross-Sectional Study of Ascaris Lumbricoides Infection in a Rural Community in Ebonyi State, Nigeria: Prevalence and Risk Factors. Iran Journal of Public Health, 44, 1430-1432.

[54] Nnachi, I.A., Odikamnoro, O.O., Nnachi, A.U., Ani, O.C., Uhuo, C.A. and Egwuatu, C.C. (2015) Epidemiology of Hookworm Infection and the Influence of Some Epidemiological Factors on Their Prevalence in Some Farming Communities in Ebonyi State, Nigeria. International Journal of Tropical Disease, 10, 1-10. https://doi.org/10.9734/IJTDH/2015/19916

[55] Owaka, E.E. and Njoku, O.O. (2016) Survey of Intestinal Helminth Infection 
amongst School Children in Rural Communities of Ebonyi State Nigeria. International Journal of Scientific and Research Publications, 6, 76-85.

[56] Wagbastoma, V.A. and Aisien, M.S. (2005) Helminthiasis in Selected Children Seen at the University of Benin Teaching Hospital (UBTH), Benin City, Nigeria. Nigerian Postgraduate Medical Journal, 12, 23-27.

[57] Mordi, R.M. and Ngwodo, P.O.A. (2007) A Study of Blood and Gastro-Intestinal Parasites in Edo State. African Journal of Biotechnology, 6, 2201-2207. https://doi.org/10.5897/AJB2006.000-5438

[58] Oguanya, F.C., Okogun, G.R.A., Akhile A.O., Eloka, C.C.V., Okoro, C.J. and Okpe, A.C. (2012) Prevalence of Soil-Transmitted Helminths Infections among Public Primary School Pupils in Ekpoma, Edo State, Nigeria. International Journal of Community Research, 1, 30-34.

[59] Omorodion, O.A., Isaac, C., Nmorsi, O.P.G., Ogoya, E.M. and Agholor, K.N. (2012) Prevalence of Intestinal Parasitic Infection among Tertiary Institution Students and Pregnant Women in South-South, Nigeria. Journal of Microbiology and Biotechnology Research, 2, 815-819.

[60] Akinbo, F.O., Ikedje, A. and Okaka, C.E. (2013) Intestinal Parasitic Infections among Artisans in Benin City, Nigeria. Nigeria Journal of Basic Clinical Science, 10, 66-69. https://doi.org/10.4103/0331-8540.122761

[61] Nwaneri, D.U. and Omuemu, V.O. (2013) Intestinal Helminthiasis and Nutritional Status of Children Living in Orphanages in Benin City, Nigeria. Nigerian Journal of Clinical Practice, 16, 243-248. https://doi.org/10.4103/1119-3077.110144

[62] Ogbain-Emovon, E.A., Eigbedion, A.O., Ojide, C.K. and Kalu, E.I. (2014) Prevalence and Impact of Socio-Economic/Environmental Factors on Soil-Transmitted Helminth Infection in Children Attending Clinic in a Tertiary Hospital in Benin City, Nigeria. International Journal of Basic, Applied and Innovative Research, 3 , 65-70.

[63] Emeka, L.I. (2013) Prevalence of Intestinal Helminthic Infection among School Children in Rural and Semi Urban Communities in Nigeria. IOSR Journal of Dental and Medical Sciences, 6, 61-66. https://doi.org/10.9790/0853-0656166

[64] Ukwubile, C.A., Otalu, O., Uduak, A. and Matthew, O.A. (2013) The Prevalence of Parasitic Human Intestinal Helminthes and the Efficacy of Anthelmintic Drug in Children in Uzo-Uwani Local Government Area, Enugu State, Nigeria. Open Journal of Medical Microbiology, 3, 213-218. https://doi.org/10.4236/ojmm.2013.34032

[65] Aniwada, E.C., Uleanya, N.D., Igbokwe, L.N. and Onwasigwe, C. (2016) Soil Transmitted Helminths; Prevalence, Perception and Determinants among Primary School Children in Rural Enugu State, Nigeria. International Journal of Tropical Disease and Health, 15, 1-12. https://doi.org/10.9734/IJTDH/2016/24501

[66] Uzodimma, C.E., Ojinnaka, N.C., Chukwunedum, A.U. and Anthony, N.I. (2016) Prevalence of Intestinal Helminthiasis among Children with Chronic Neurologic Disorders in University of Nigeria Teaching Hospital (UNTH) Ituku-Ozalla. Journal of Neurological Disorders, 4, Article ID: 1000258.

[67] Abaver, D.T., Nwobegahay, J.M., Goon, D.T., Iweriebor, B.C. and Anye, D.N. (2011) Prevalence of Intestinal Parasitic Infections among HIV/AIDS Patients from Two Health Institutions in Abuja, Nigeria. African Health Sciences, 11, 24-27.

[68] Kamalu, N.A., Uwakwe, F.E. and Opara, J.A. (2013) Prevalence of Intestinal Parasite among High School Students in Nigeria. Academic Journal of Interdisciplinary Studies, 2, 9-16.

[69] Kalu, M.K., Eugene, C.N. and Ifeanyi, A.O. (2013) Intestinal Nematode Parasites 
amongst School Children Attending Some Primary Schools in Mbaitoli Local Government Area, Imo State, Nigeria. Journal of Biological Sciences and Bioconservation, 5, 102-110.

[70] Ezeigbo, O.R., Ezike, M.N., Ajuga, M.U., Ohiara, S. and Kalu, S. (2014) Soil Transmitted Helminthes among Pupils in Mgbidi, Oru-West Local Government Area of Imo State, Nigeria. Wudpecker Journal of Medical Sciences, 3, 27-32.

[71] Udensi, J.U., Mgbemena, I.C., Emeka-Nwabunnia, I., Ugochukwu, M.G. and Awurum, I.N. (2015) Prevalence of Intestinal Parasites among Primary School Children in Three Geopolitical Zones of Imo State, Nigeria. Science Journal of Public Health, 3, 25-28. https://doi.org/10.11648/j.sjph.s.2015030501.15

[72] Kalu, E.C., Emeka, R.H. and Pascal, O.K. (2015) An Evaluation of Infection with Intestinal Helminths among Pupils in Rural Communities in Gwagwada District, Nigeria. African Journal of Parasitology Research, 2, 104-107.

[73] Iwunze, J.I., Amaechi, A.A., Iheme, J.N., Njoku, F.U. and Odemenam, C.C. (2017) Prevalence of Intestinal Parasites among Primary School Children in Obowo L.G.A of Imo State, Nigeria. American Journal of Environmental and Geoscience, 1, 29-33.

[74] Yahaya, A., Tyav, Y.B. and Idris, A. (2015) Prevalence of Intestinal Parasitic Helminths from Fingernails of "Almajiris" in Birnin Kudu Local Government Area, Jigawa State, Nigeria. International Journal of Tropical Disease and Health, 8, 66-74. https://doi.org/10.9734/IJTDH/2015/14186

[75] Auta, T., Kogi, E. and Oricha, K.A. (2013) Studies on the Intestinal Helminths Infestation among Primary School Children in Gwagwada, Kaduna, North Western Nigeria. Journal of Biology, Agriculture and Healthcare, 3, 48-53.

[76] Thomas, H.Z., Jatau, E.D., Inabo, H.I. and Garba, D.D. (2014) Prevalence of Intestinal Helminths among Primary School Children in Chikun and Kaduna South Local Government Areas of Kaduna State, Nigeria. Journal of Medicine and Medical Research, 2, 6-11.

[77] Auta, T., Reuben, W.J., Abdulhadi, J.B. and Mohammed, J.A. (2014) A Comparative Study on the Prevalence of Intestinal Helminths among Rural and Sub-Urban Pupils in Gwagwada, Nigeria. Journal of Parasitology and Vector Biology, 5, 87-91.

[78] Ahmad, M.M., Abubakar, M.M. and Shuaibu, I. (2015) Study of Some Major Intestinal Helminthes among Primary School-Age Children in Wudil, Kano, Nigeria. Dutse Journal of Pure and Applied Sciences, 1, 66-71.

[79] Oluwole, A.S., Isiyaku, S., Aliero, A.A., Nwosu, C., William, A., Elhassan, E. and Ekpo, U.F. (2017) Assessment of the Burden of Soil-Transmitted Helminthiasis After Five Years of Mass Drug Administration for Onchocerciasis and Lymphatic Filariasis in Kebbi State, Nigeria. Parasite Epidemiology and Control, 2, 21-29. https://doi.org/10.1016/j.parepi.2017.01.002

[80] Ejima, I.A.A. and Ajogun, R.T. (2011) The Prevalence and Health Implications of the OVA of Human Intestinal Helminths Parasites Isolated from Faeces Collected near Students' Hostels, Federal Polytechnic, Idah, Kogi State, Nigeria. International Journal of Tropical Medicine, 6, 15-18. https://doi.org/10.3923/ijtmed.2011.15.18

[81] Babatunde, S.K., Adedayo, M.R., Ajiboye, A.E., Sunday, O. and Ameen, N. (2013) Soil-Transmitted Helminth Infections among School Children in Rural Communities of Moro Local Government Area, Kwara State, Nigeria. African Journal of Microbiology Research, 7, 5148-5153. https://doi.org/10.5897/AJMR2013.6258

[82] Saka, M.J., Aremu, A.S. and Saka, A.O. (2014) Soil-Transmitted Helminthiasis: Prevalence Rate and Risk Factors among School Children in Ilorin, Nigeria. Journal of Applied Sciences in Environmental Sanitation, 9, 139-145. 
[83] Babamale, O.A., Shittu, O., Danladi, Y.K., Abdulraheem, J.Y. and Ugbomoiko, U.S. (2016) Pattern of Plasmodium-Intestinal Helminth Co-Infection among Pregnant Women in a High Transmission Zone of Malaria in Nigeria. Asian Pacific Journal of Tropical Disease, 6, 424-428. https://doi.org/10.1016/S2222-1808(16)61060-5

[84] Amaechi, E.C., Nwadike, C.C., Musa, A.L., Ohaeri, C.C., Ukpai, O.M. and Ejike, B.U. (2016) Malaria and Soil-Transmitted Helminthes Coinfection in a Rural Community of Kwara State, North Central Nigeria. Brazilian Journal of Biological Sciences, 3, 331-339. https://doi.org/10.21472/bjbs.030609

[85] Bolaji, O.S., Akinleye, C.A., Agunbiade, B.T., Adeyemo, A.O., Bakare, O.E. and Adeyeba, O.A. (2017) Survey of Intestinal Schistosomiasis and Soil-Transmitted Helminthiasis among Pupils in Ifelodun, Kwara State Nigeria. Journal of Bio Innovation, 6, 78-90.

[86] Adeoye, G.O., Osayemi, C.O., Oteniya, O. and Onyemekeihia, S.O. (2007) Epidemiological Studies of Intestinal Helminths and Malaria among Children in Lagos, Nigeria. Pakistan Journal of Biological Sciences, 10, 2208-2212. https://doi.org/10.3923/pjbs.2007.2208.2212

[87] Ibidapo, C.A. and Okwa, O. (2008) The Prevalence and Intensity of Soil Transmitted Helminths in a Rural community, Lagos Suburb, South West Nigeria. International Journal of Agriculture and Biology, 10, 89-92.

[88] Ajayi, M.B., Sani, A.H., Ezeugwu, S.M.C., Afocha, E.E. and Adesesan, A.A. (2017) Intestinal Parasitic Infection and Body Mass Index among School Children in Oshodi Lagos, Nigeria. Advances in Cytology and Pathology, 2, Article ID: 00015.

[89] Eke, S.S., Omalu, I.C.J., Otuu, C.A., Hassan, S.C., Ibrahim, S. and Boyi, A.A. (2014) Hookworm Infection among Humans in Panda, Panda Development Area, Karu LGA of Nasarawa State, Nigeria. $I J A B R, 6,66-73$.

[90] Omalu, I.C.J., Paul, S., Adeniran, L.A., Hassan, S.C., Pam, V.A., Eke, S.S. and Eze, G.C. (2013) Assessment of the Level of Gastrointestinal Parasites Infection among Food Vendors in Minna, North Central Nigeria. Annual Review and Research in Biology, 3, 705-713.

[91] Okonko, I.O., Soleye, F.A., Amusan, T.A., Mejeha, O.K., Babalola, E.T. and Adekolurejo, O.A. (2009) Detection and Prevalence Intestinal Parasites in Patients in Abeokuta, Southwestern, Nigeria. World Applied Science Journal, 7, 1183-1187.

[92] Sam-Wobo, S.O., Asiwaju, R., Idowu, O.A., Eromosele, C.O. and Adeleke, M.A. (2012) Communal Evaluation of Intestinal Helminths in Some Guineaworm-Controlled Communities in Ogun State, Nigeria. Journal of Entomology and Nematology, 4, 7-11. https://doi.org/10.5897/JEN11.019

[93] Akingbade, O.A., Akinjinmi, A.A., Ezechukwu, U.S., Okerentugba, P.O. and Okonko, I.O. (2013) Prevalence of Intestinal Parasites among Children with Diarrhea in Abeokuta, Ogun State, Nigeria. Researcher, 5, 66-73.

[94] Banjo, T.A., Amoo, A.O.J., Busari, A., Kama, A.C., Lawal, I.A., Ogundahunsi, O.A., Olooto, W.E., Familoni, O.B., Onilude, A.A., Mutiu, W.B., Oyelere, K.A. and Kama, G. (2013) Intestinal Parasites among Abattoir Workers in Abeokuta. American Journal of Research Communication, 1, 84-96.

[95] Simon-Oke, I.A., Afolabi, O. and Afolabi, T. (2014) The Prevalence of Soil Transmitted Helminths among School Children in Ifedore Local Government Area of Ondo State, Nigeria. European Journal of Biology and Medical Science Research, 2, $17-22$.

[96] Akinseye, J.F., Nmorsi, O.P.G. and Akinbolaji, T.J. (2015) Human Soil-Transmitted Helminthiasis among Adolescents in Ilara-Mokin Community, Ondo State, Nigeria; 
A Case Study of Ascaris lumbrecoides, Trichuris trichuira and Hookworm. International Journal of Life Sciences Research, 3, 108-112.

[97] Dada, E.O. and Aruwa, C.E. (2015) Prevalence of Human Intestinal Helminth Parasites among Undergraduate Students at the off Campus (North Gate Area), Federal University of Technology, Akure (Futa), Nigeria. Open Access Library Journal, 2, e1399.

[98] Akinseye, F.J., Egbebi, A.O. and Fadare, O.S. (2017) Challenges of Soil-Transmitted Helminthiasis in Some Communities in Ondo State, Nigeria. International Journal of Advanced Research in Biological Sciences, 4, 164-171. https://doi.org/10.22192/ijarbs.2017.04.03.019

[99] Kirwan, P., Asaolu, S.O., Molloy, S.F., Abiona, T.O., Jackson, A.L. and Holland, C.V. (2019) Patterns of Soil-Transmitted Helminth Infection and Impact of Four-Monthly Albendazole Treatments in Preschool Children from Semi-Urban Communities in Nigeria: A Double-Blind Placebo-Controlled Randomised Trial. BMC Infectious Diseases, 9, 20. https://doi.org/10.1186/1471-2334-9-20

[100] Awolaju, B.A. and Morenikeji, O.A. (2009) Prevalence and Intensity of Intestinal Parasites in Five Communities in South-West Nigeria. African Journal of Biotechnology, 8, 4542-4546.

[101] Ojurongbe, O., Awe, F., Olowe, O., Okanlawon, B. and Adeyeba, O. (2010) Prevalence of Soil Transmitted Helminth Infections in a Tertiary Institution in Western Nigeria. New York Science Journal, 3, 1-5.

[102] Ojurongbe, O., Oyesiji, K.F., Ojo, J.A., Odewale, G., Adefioye, O.A., Olowe, A.O., Opaleye, O.O., Bolaji, O.S. and Ojurongbe, T.A. (2014) Soil Transmitted Helminth Infections among Primary School Children in Ile-Ife Southwest, Nigeria: A Cross-Sectional Study. International Research Journal of Medicine and Medical Sciences, 2, 6-10.

[103] Salawu, S.A. and Ughele, V.A. (2015) Prevalence of Soil-Transmitted Helminths among School-Age Children in Ife East Local Government Area, Osun State, Nigeria. FUTA Journal of Research in Sciences, 11, 139-151.

[104] Olaniran, O., Ajayi, O.O., Odetoyin, B.W., Afolayan, D.O., Awoyeni, E.A., Adekunle, O.T. and Oyetoke, O.O. (2015) Prevalence of Soil Transmitted Helminthes among School Children in Central Local Government Area, Ile-Ife, Osun State, Nigeria. International Journal of Novel Research in Interdisciplinary Studies, 2, 8-13.

[105] Fafunwa, T.S., Mogaji, H.O., Oluwole, A.S., Adeniran, A.A., Fagbenro, M.T., Sam-Wobo, S.O., Bada, B.S. and Ekpo, U.F. (2017) Water Resource, Hygienic Practice, and Soil Transmitted Helminthiasis in Some Rural Communities of Osun State, Nigeria. Journal of Water Resource and Protection, 9, 99-110. https://doi.org/10.4236/jwarp.2017.92008

[106] Alli, J.A., Okonko, I.O., Kolade, A.F., Nwanze, J.C., Dada, V.K. and Ogundele, M. (2011) Prevalence of Intestinal Nematode Infection among Pregnant Women Attending Antenatal Clinic at the University College Hospital, Ibadan, Nigeria. Advances in Applied Science Research, 2, 1-13.

[107] Damen, J.G., Lar, P., Mershak, P., Mbaawuga, E.M. and Nyary, B.W. (2010) A Comparative Study on the Prevalence of Intestinal Helminths in Dewormed and Non-Dewormed Students in a Rural Area of North-Central Nigeria. Lab Medicine, 41, 585-589. https://doi.org/10.1309/LM0FJMG1JOD5KLTG

[108] Jombo, G.T.A., Damen, J.G., Amechi, I., Etukudo, N.S., Dabit, O., Panchabhai, V.B. and Bardia, M.R. (2011) Intestinal Parasitosis among Undernourished Children of an Urban Settlement in West Africa: Pattern and Types. International Infectious 
Diseases, 1, 1-7.

[109] Abelau, M.L., Goselle, O.N., Udeh, E.O., DPopova, D.D. and Popov, T.V. (2011) A Comparative Study of the Prevalence of Helminth Parasites in HIV Seropositive and HIV Seronegative Individuals in Plateau State, Nigeria. Nigerian Annals of Natural Sciences, 11, 22-32.

[110] Mamman, A.S. and Reuben, C.R. (2014) Intestinal Helminthiasis among Inmates of Jos Prison, Plateau State, Nigeria. World Journal of Biology and Biological Sciences, 2, 67-71.

[111] Afolaranmi, T.O., Hassan, Z.I., Bello, D.A., Tagurum, Y.O., Augustine, D.P., Joro, S.M. and Zoakah, A.I. (2015) Pattern of Intestinal Helminthiasis among under Five in a Rural Community of Plateau State, Nigeria. E3 Journal of Scientific Research, 3, 15-20.

[112] Odu, N.N., Elechi, V.I. and Okonko, I.O. (2013) Prevalence of Intestinal Helminths Infection among Primary School Children in Urban and Semi-Urban Areas in Port Harcourt, Rivers State, Nigeria. World Rural Observations, 5, 52-61.

[113] Mohammed, K., Abdullah, M.R. and Omar, J. (2015) Intestinal Parasitic Infection and Assessment of Risk Factors in North-Western, Nigeria: A Community Based Study. International Journal of Pharma Medicine and Biological Sciences, 4, 141-145.

[114] Shehu, M.M., Kabiru, A., Abubakar, U. and Muhammad, K. (2013) Prevalence of Intestinal Helminth Infections among School Children in Relation to Occupation of Parents and Toilets Facilities in Maru LGA Zamfara State. Journal of Biology, Agriculture and Healthcare, 3, 87-90.

[115] Tchuem Tchuenté, L.A. (2011) Control of Soil-Transmitted Helminths in Sub-Saharan Africa: Diagnosis, Drug Efficacy Concerns and Challenges. Acta Tropica, 120, S4-S11. https://doi.org/10.1016/j.actatropica.2010.07.001

[116] Odinaka, K.K., Nwosu, E.C., Mbanefo, F., Iheakaram, A.C. and Okolo, S. (2015) Prevalence and Pattern of Soil-Transmitted Helminthic Infection among Primary School Children in a Rural Community in Imo State, Nigeria. Journal of Tropical Medicine, 2015, 2-4.

[117] Ugbomoiko, U.S., Onajole, A.T. and Edungbola, L.D. (2006) Prevalence and Intensity of Geo-Helminths Infection in Oba-Ile Community of Osun State, Nigeria. $\mathrm{Ni}$ gerian Journal of Parasitology, 27, 62-67.

[118] Otto, G.F. (1929) A Study of the Moisture Requirements of the Eggs of the Horse, the Dog, Human and Pig Ascarids. American Journal of Hygiene, 10, 497-520. https://doi.org/10.1093/oxfordjournals.aje.a112765

[119] Spindler, L.A. (1929) The Relation of Moisture to the Distribution of Human Trichuris and Ascaris. American Journal of Hygiene, 10, 476-496.

[120] Chammartin, F., Hürlimann, E., Raso, G., N’Goran, E.K., Utzinger, J. and Vounatsou, P. (2013) Statistical Methodological Issues in Mapping Historical Schistosomiasis Survey Data. Acta Tropica, 128, 345-352. https://doi.org/10.1016/j.actatropica.2013.04.012

[121] Lai, Y.S., Zhou, X.N., Utzinger, J. and Vounatsou, P. (2013) Bayesian Geostatistical Modelling of Soil Transmitted Helminth Survey Data in the People's Republic of China. Parasites \& Vectors, 6, 359. https://doi.org/10.1186/1756-3305-6-359

[122] Pullan, R.L., Gething, P.W., Smith, J.L., Mwandawiro, C.S., Sturrock, H.J.W., et al. (2011) Spatial Modelling of Soil-Transmitted Helminth Infections in Kenya: A Disease Control Planning Tool. PLOS Neglected Tropical Diseases, 5, e958. https://doi.org/10.1371/journal.pntd.0000958 